Article

\title{
A Novel Servovalve Pilot Stage Actuated by a Piezo-electric Ring Bender: A Numerical and Experimental Analysis
}

\author{
Paolo Tamburrano ${ }^{1, *}$, Andrew R. Plummer ${ }^{2}$, Pietro De Palma ${ }^{1}$, Elia Distaso ${ }^{1}$ and \\ Riccardo Amirante 1 \\ 1 Department of Mechanics, Mathematics and Management (DMMM), Polytechnic University of Bari, \\ 70125 Bari, Italy; pietro.depalma@poliba.it (P.D.P.); elia.distaso@poliba.it (E.D.); \\ riccardo.amirante@poliba.it (R.A.) \\ 2 Centre for Power Transmission and Motion control (PTMC), University of Bath, Bath BA2 7AY, UK; \\ A.R.Plummer@bath.ac.uk \\ * Correspondence: paolo.tamburrano@poliba.it
}

Received: 26 December 2019; Accepted: 27 January 2020; Published: 4 February 2020

\begin{abstract}
Electrohydraulic servovalves are widely used for precise motion control in aerospace and other industries due to their high accuracy and speed of response. However, commercial two-stage servovalves have several undesirable characteristics, such as the power consumption caused by the quiescent flow (internal leakage) in the pilot stage, and the complexity and high number of parts of the torque motor assembly, which affect the cost and the speed of manufacture. The solution to these problems can help to reduce costs, weight and power consumption, and enhance the reliability and reproducibility as well as the performance of these valves. For these reasons, this paper proposes a novel configuration for the pilot stage: it is composed of two normally closed two-way two-position (2/2) valves actuated by two piezo-electric ring benders; the opening and closing of the two piezo-valves can generate a differential pressure to be used to control the displacement of the main spool. In this way, there is negligible quiescent flow when the main stage is at rest; in addition, the torque motor and all its components are removed. To assess the performance of this novel pilot stage concept, a prototype of the piezo-valve has been constructed and tested. The experimental results indicate that the response speed of the new piezo-valve is very high. Furthermore, a numerical model is employed to show that, by adjusting specific parameters, the performance of the piezo-valve can be further improved, so that the valve can be fully opened or closed in less than $5 \mathrm{~ms}$.
\end{abstract}

Keywords: servovalves; internal leakage; piezoelectric actuators; ring bender

\section{Introduction}

The architectures of commercially available two-stage servovalves have not substantially changed for many years, since they can provide high reliability and excellent dynamics [1]. Most valves make use of either a double nozzle-flapper pilot stage or a deflector jet pilot stage depending on the applications, the former being more used in industrial applications, whilst the latter is more frequently used in aircrafts [2]. Regardless of the pilot stage, the main stage is usually a spool valve in which the main spool is actuated by a differential pressure generated at its extremities by the pilot stage. In this way, very high actuation forces are generated, providing fast respond speeds and capability of shearing chips that might be jammed between the metering edges [2]. The force levels developed are much higher than proportional valves or on/off valves using solenoids to directly drive the spool [3-10], which results in a much faster response and higher shear forces. These characteristics have led to widespread use of these servovalve designs, which are fundamental components in closed-loop electro-hydraulic motion 
control systems demanding high performance levels, both in industrial and aeronautical applications. In the latter field, for instance, two stage servo-valves are used for engine fuel control, brake and steering control, and for primary flight controls (actuation of elevators, ailerons and rudders), the total number of valves being about 40 on a typical airliner.

However, even though these architectures have been widely used and have not been substantially changed for many years, they present some week points that are still unsolved, such as:

(1) The pilot stage requires a quiescent flow rate to work, to be referred to as the internal leakage of the pilot stage (note that the overall internal leakage is the sum of this contribution and a second contribution given by the internal leakage in the main stage). Although it is small compared to the nominal flow rate of a valve, the internal leakage in the pilot stage is continuous and constant regardless of the opening degree of the main stage, thus causing unwanted power consumption during operation $[1,2]$.

(2) The electromagnetic torque motor assembly is also a major issue associated with these valves because it is composed of many sensitive mechanical and electrical parts that penalise simplicity, set-up, duration of manufacture and manufacturing costs. Of these components, the flexure tube, used to support the flapper while separating the torque motor from the hydraulic fluid, is the most critical. Indeed, it needs to be manufactured very accurately to ensure the stiffness required [1,2]. Moreover, the flapper-flexure tube system is very sensitive to vibration, and a valve may experience fatigue failure of the flexure tube due to excessive bending under vibration, in addition to the fact that the oscillations of the flapper caused by external noise may result in a change of the valve output [1,2].

To date, research studies in the scientific literature have mainly been focused on the reduction of the complexity of servovalves (namely, solutions to drawback 2 previously explained). In particular, a promising research field aims to replace the electromagnetic torque motor assembly with piezoelectric actuators, thus reducing complexity and manufacturing costs [2]. Different types of piezoelectric actuators have been used to directly drive the main stage spool or to drive the flapper, jet pipe or deflector jet in the pilot stage [11-21], showing that the idea of using a piezo-electric actuator to drive a servovalve is feasible and promising. One of the commercially available piezoelectric actuators that has been used for this purpose is the stack-type, in which several piezo elements are joined together to form a multi-layer actuator [11-13]; in parallel to piezo-stacks actuators, also amplified piezo-stack actuators, which can provide higher displacement but lower forces, have been proposed to replace the torque motors in servovalves [14-16]. However, both piezo-stack actuators and amplified piezo-stack actuators seem to be too heavy and large to be employed in servovalves, which must be compact and light, especially for applications in aircraft. As an alternative to stack actuators, lighter piezo-actuators, such as rectangular benders, have been employed in novel designs to drive the pilot stage of servovalves in place of the torque motor [17-19]; in this case, the main deficit is the very low actuation forces obtained with these actuators.

Instead, the most promising solution for these applications seems to be "the ring bender", which is a flat annular piezo-disc deforming in a concave or convex fashion depending on the polarity of the applied voltage, providing a very good compromise between actuation force and displacement, while being sufficiently compact for this type of applications. In this regard, in [20,21], two ring benders, mounted in tandem to provide redundancy, were used in place of the torque motor to drive the flapper in a double flapper-nozzle pilot stage. The preliminary results obtained in $[20,21]$ prove the feasibility, in terms of actuation forces, displacement and dimensions, of using ring benders as actuators for the pilot stages of servovalves.

As alternatives to piezo-electric actuators, giant magneto-strictive materials (GMMs) have been proposed to be used for the actuation of servovalves. These new actuators, appeared in recent years, can change their shape and length under the influence of an external magnetic field, thus producing strain with very fast response speed and large forces [22]. In [23], a deflector-jet servovalve using a GMM 
was developed; instead, in [24] a GMM was used to drive a flapper-nozzle servovalve. Other examples of application of GMMs in servovalves are provided in $[25,26]$. As for piezo-stack actuators, the main problem associated with GMMs appears to be the large dimensions of these actuators, too bulky to be implemented in commercial servovalves.

All the above-mentioned research studies have had the objective of reducing the complexity of servovalves. However, to date the problem concerning the internal leakage (drawback 1 previously explained) has not been addressed in the scientific literature, apart from the work presented in [27], in which a small spool actuated by a ring bender was employed for the pilot stage in order to minimise the internal leakage of the pilot stage.

In this scenario, the present research aims at developing a novel configuration for the pilot stage by using piezo-electric ring benders. The proposed architecture is capable of reducing both the overall internal leakage when the main spool is in the neutral position and the complexity of the pilot stage, because the torque motor and all the associated components are removed. The novel valve concept, with all the associated advantages, is thoroughly described in the following section.

\section{Materials and Methods}

\subsection{Novel Servovalve Concept}

Figure 1 shows a representation of a typical four-way three-position (4/3) double nozzle-flapper servovalve. This valve, along with the deflector jet servovalve (which has a very similar operating principle), is the most-used two-stage servovalve design by virtue of the strong points explained in the introduction [2].

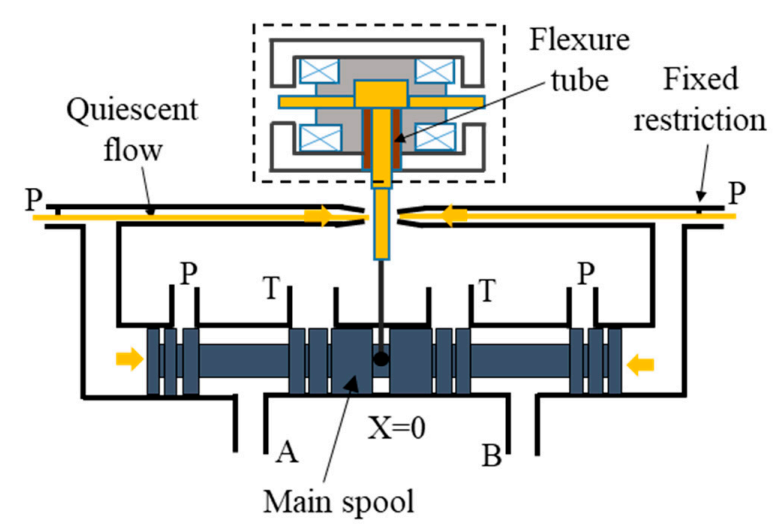

(a)

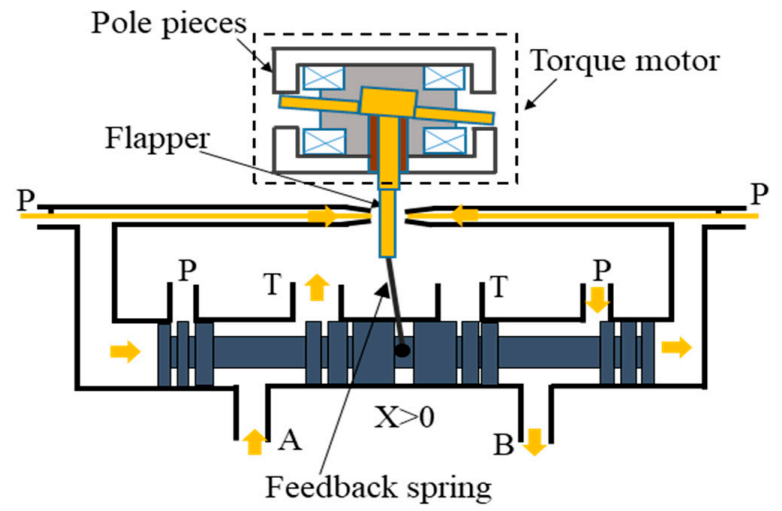

(b)

Figure 1. Operating principle of a double nozzle-flapper servovalve: spool not modulating flow (a) and flow modulation $(\mathbf{b})$. 
As shown in Figure 1a, when the main spool is not modulating flow, the coils of the torque motor are not excited, and the flapper is in the central position between the two nozzles. Although no flow is sent to the actuator, a quiescent flow of oil is needed trough the two nozzles in order to maintain the same pressure at the spool extremities. When it is needed to modulate flow (Figure 1b), the coils are excited, and the generated magnetic field makes the flapper rotate from the central position towards one of the two nozzles according to the input current. The flapper movement creates a pressure difference between the extremities of the main spool, which is forced to move. While moving, the spool drags the feedback spring, which creates a restoring torque on the flapper assembly. The spool continues moving until the restoring torque equals the torque exerted by the torque motor. In place of this mechanical feedback, some valves have electrical feedback obtained by means of linear variable differential transformers (LVDTs). As already mentioned in the introduction, this pilot stage architecture is very complex in addition to causing continuous power consumption due to the quiescent flow (internal leakage) which is continuous and constant regardless of the spool position.

This architecture is well established, and its performance parameters are widely known [2]. The quiescent flow in the pilot stage, also known as tare leakage, can vary depending on the operating pressure and on the size of the valve, and it can be as high as $0.73 \mathrm{~L} / \mathrm{min}$ for commercially available units [2].

Figure 2 shows the proposed valve design. Each piezo-valve is a very simple two-way two-position $(2 / 2)$ valve that has the advantage of being normally closed, which means that the ring bender stops the oil flow when the spool is at null. This can represent a huge improvement in terms of power consumption compared to the typical configuration shown in Figure 1, since the quiescent flow becomes negligible in the pilot stage when the main spool is at null, as shown in Figure 2a.

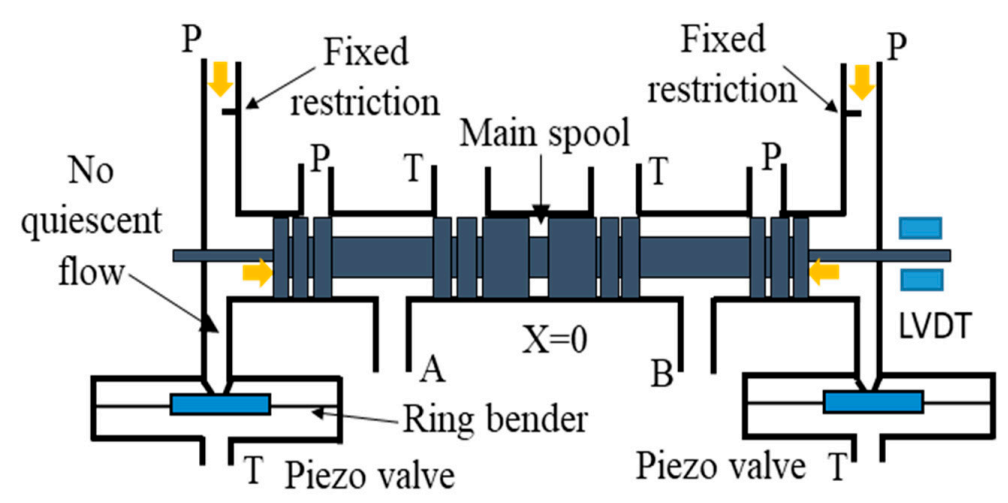

(a)

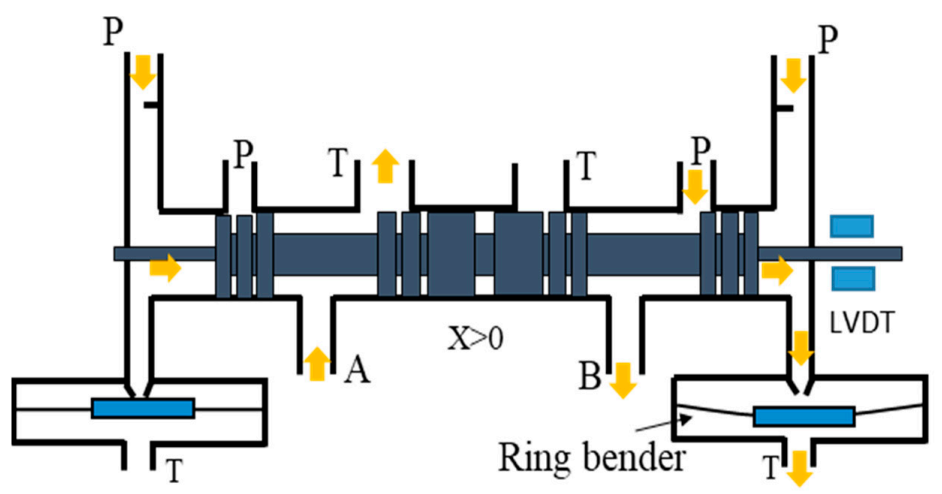

(b)

Figure 2. Operating principle of the novel servovalve actuated by two ring benders: spool not modulating flow (a) and flow modulation (b). 
In addition, the comparison between Figures 1 and 2 shows that, in the new configuration, the torque motor and its critical components are removed, namely, the pole pieces, the armatures, the flapper, the flexure tube and the feedback spring. In place of these components, two ring benders and two closure members are needed, along with a linear variable differential transformer (LVDT) for a closed loop control.

The assembly of the torque motor, flapper, flexure tube and feedback spring, which is an expensive system in terms of cost and manufacturing time, is no longer needed in the proposed configuration. The novel concept also avoids the problem concerning the fatigue failure of the flexure tube due to excessive bending under vibration, and the possible change in the valve output due to the oscillations of the flapper caused by external noise.

The feasibility of the proposed solution was already demonstrated in reference [28], employing a simulation model of the full valve concept. The simulations showed that this valve architecture has a high potential in terms of response speed, in addition to minimising the internal leakage.

The good results achieved in [28] prompted the authors of the present work to construct a prototype of one of the two 2/2 normally closed piezo-valves representing the novel pilot stage concept. The prototype was tested in a hydraulic test rig located at the Fluid Power Laboratory of the Centre of Power Transmission and Motion Control (PTMC) of the University of Bath. The prototype and the test rig are described in the next section.

\subsection{Valve Prototype and Hydraulic Test Rig}

The valve prototype and the test rig were constructed and assembled in order to test one of the two piezo-valves modulating the pressure at the main spool extremities. The test rig reproduces the right part (or, equivalently, the left part) of the valve concept shown in Figure 2, being composed of the following elements: supply line $(\mathrm{P})$, fixed restriction, piezo-valve and chamber comprised between the fixed restriction, the spool end and the piezo-valve. A schematic representation and a photograph of the test rig are shown in Figure 3a,b, respectively. The supply line is composed of a volumetric pump (1), a non-return valve (2), a pressure relief valve (3) and an accumulator (4). A pressure transducer (5) is positioned upstream of the restriction (6), whose area can be changed manually. This restriction represents the fixed restriction shown in Figure 2, with the difference that, in the test rig, its flow area can be adjusted. The pressure drop across the restriction is measured by a second pressure transducer (7). After the restriction (6), the oil can enter the piezo-valve, whose components are positioned inside a case (8). An adjuster (9) is mounted inside the valve body through a nut so that the position of the nozzle (10) can be varied with respect to the closure member (11). In this way, it is possible to provide the ring bender with a pre-compression to close the valve effectively. The closure member (11) is inserted through the hole of the ring bender (12), and the latter is fixed to the valve body using elastomers o-rings (13). This choice secures the mechanical integrity of the ring bender while deforming inside the valve. The position of the closure element (therefore, the displacement of the ring bender) is measured through an eddy current sensor (14). Another adjustable mechanical stop (15) is also employed in order to allow the maximum displacement of the ring bender (i.e., the maximum opening of the valve) to be regulated. The pressure of the oil discharged from the piezo-valve is measured by a pressure transducer (16).

Note that the volume comprised between the restriction (6) and the nozzle (10) represents the volume of Figure 2 comprised between the fixed restriction, the spool end and the nozzle of the piezo-valve.

The picture of the test rig (Figure 3b) shows the pressure transducer (5), the variable restrictor (6), the pressure transducer (7), the valve case (8), the adjusters (9) and (15) and the pressure transducer (16). 


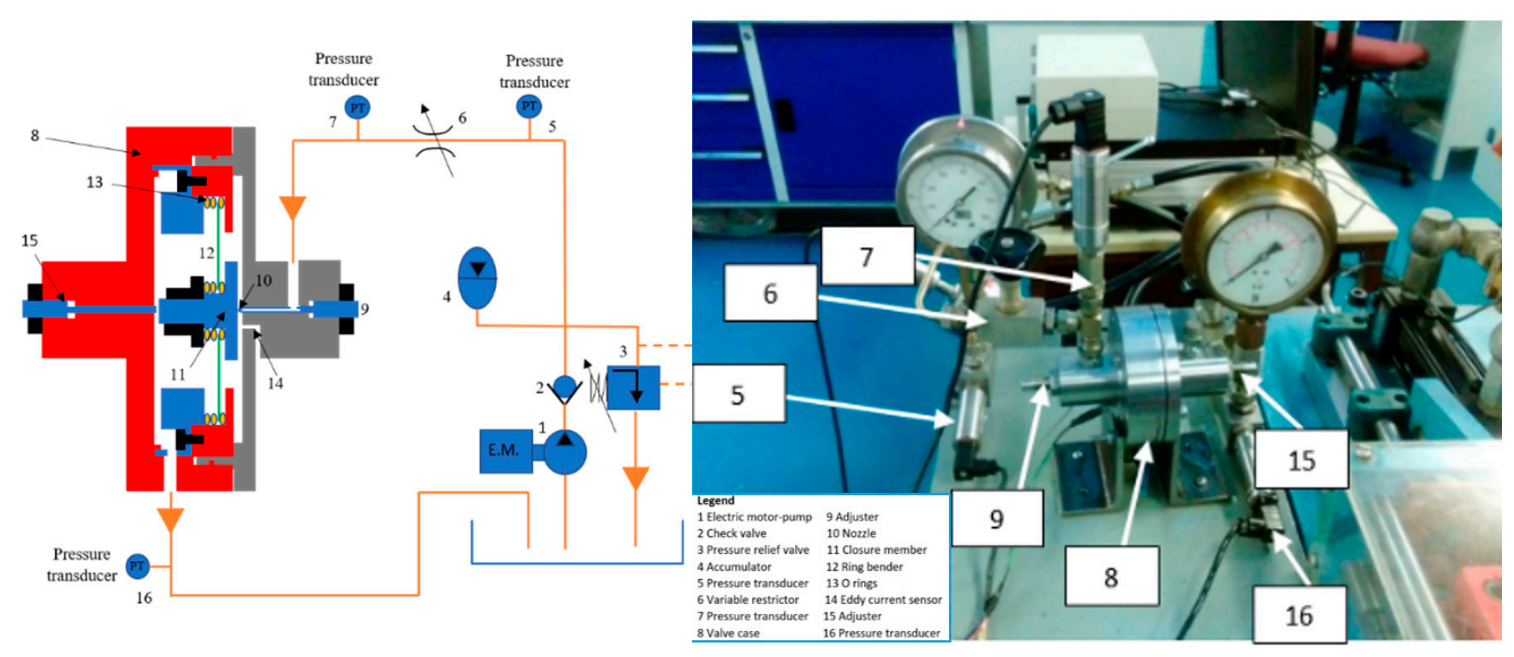

(a)

(b)

Figure 3. Schematic representation (a) and photograph of the test rig (b).

An external PC and a LabVIEW code are used to control the test rig and to acquire the signals from the transducers with a sample frequency of $10 \mathrm{kHz}$. The control signal is a control voltage (from $-5 \mathrm{~V}$ to $+5 \mathrm{~V}$ ) sent to the amplifier, which transforms this signal into a high voltage signal (from $-100 \mathrm{~V}$ to $+100 \mathrm{~V}$ ) applied to the ring bender. The pressure transducers are strain gages with a measurement error lower than $1 \%$ of the full scale (100 bar). Both the amplifier and the ring bender (model CMBR07) were purchased from the manufacturer Noliac [29]. The characteristics of the ring bender (as provided by the manufacturer) and the main geometrical parameters are reported in Table 1 . The tests were performed using ISO VG 32 hydraulic oil at a temperature of approx. $50{ }^{\circ} \mathrm{C}$ (oil density $=851 \mathrm{~kg} / \mathrm{m}^{3}$ and viscosity $=22.0 \mathrm{cSt}$ ).

Table 1. Main geometrical parameters of the test rig (+ denotes opening direction; - denotes closing direction).

\begin{tabular}{cc}
\hline Parameter & Value \\
\hline Outer diameter of the ring bender & $40 \mathrm{~mm}$ \\
Inner diameter of the ring bender & $8 \mathrm{~mm}$ \\
Height of the ring bender & $0.7 \mathrm{~mm}$ \\
Maximum theoretical displacement of the ring bender & $\pm 185 \mu \mathrm{m}$ \\
Maximum theoretical force of the ring bender & $\pm 13 \mathrm{~N}$ \\
Operating voltage of the ring bender & $\pm 100 \mathrm{~V}$ \\
Diameter of the nozzle (10) & $1 \mathrm{~mm}$ \\
Equivalent length of the oil chamber between the & $60 \mathrm{~mm}$ \\
restriction (6) and the nozzle (10) & $20 \mathrm{~mm}$ \\
$\begin{array}{c}\text { Equivalent diameter of the oil chamber between the } \\
\text { restriction (6) and the nozzle (10) } \\
\text { Area of the restriction (6) }\end{array}$ & Variable \\
Mass of the moving parts of the piezo-valve (closure \\
member, ring-bender, o-rings)
\end{tabular}

It must be noted that the aim of this experimental activity has been to evaluate the effectiveness of the piezo-valve in terms of response speed of the ring bender, pressure change at point (7) and leakage. At this point of the experimental study, the minimisation of the volume of the valve case (8) is not important for a fluid dynamic study of the valve. Instead, for commercial designs, the volume of the case can be reduced to ensure compactness and low weight; this is not a difficult task, considering that the ring bender is very small (it has a diameter of $4 \mathrm{~cm}$ and a height of $0.7 \mathrm{~mm}$ ), and the case can have 
similar dimensions, provided that the closure member is designed as compact as possible. The effect of the mass of the closure member upon the valve performance will be assessed in the final section of this paper.

\subsection{Numerical Model of the Piezo-Valve}

A numerical model simulating the test rig shown in Figure 3, and hence, the right part (or, equivalently, the left part) of the valve concept shown in Figure 2, has been developed. The equations of the numerical model, which have been implemented into the Simscape Fluids environment [30], are described in the following. The symbolism shown in Figure 3 is used to describe the numerical model.

A picture of the Simscape model is given in Figure 4. The pump, pressure relief valve and accumulator are simulated through a "Hydraulic pressure source", which is an ideal source of hydraulic energy able to maintain a specific pressure at its outlet regardless of the flow rate consumed by the system [30].

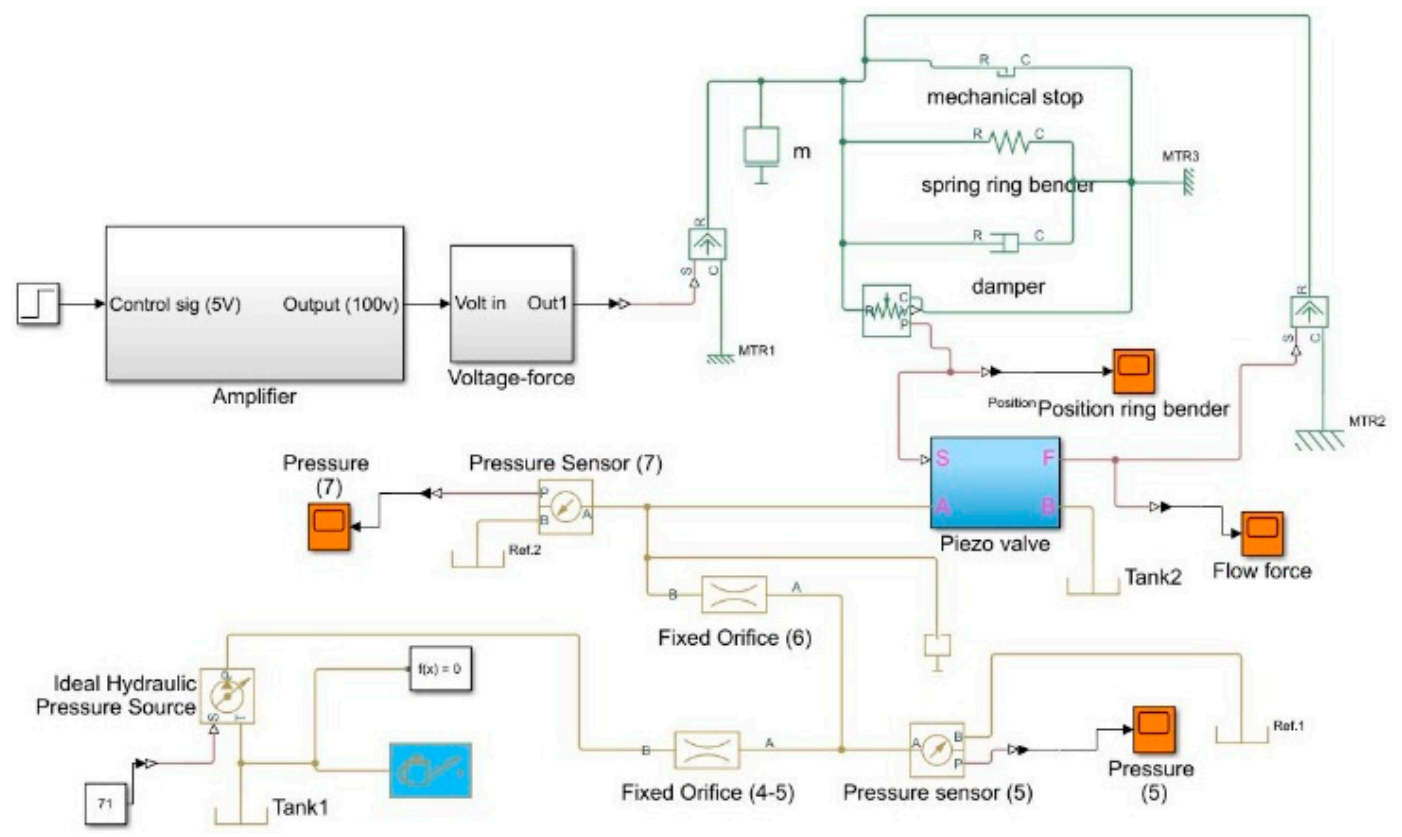

Figure 4. Simscape model employed for the numerical analysis.

The pressure drop from the supply line (4) to the pressure transducer (5), and across the variable restrictor (6), is simulated using the orifice equation [2,30,31]:

$$
q=C_{D} A_{r} \sqrt{\frac{2 \Delta p}{\rho_{0}}},
$$

where $q$ is the volumetric flow rate, $C_{D}$ is the discharge coefficient, $A_{r}$ is the restriction area, $\Delta p$ is the pressure drop and $\rho_{0}$ is the fluid density at atmospheric conditions.

The volume of oil comprised between the restriction (6) and the nozzle (10) is simulated using a block named "Constant Volume Hydraulic Chamber". Using this block, a chamber of volume $V_{0}$ with rigid walls is simulated and the fluid compressibility is taken into account. The volume of the chamber in the experimental set-up is evaluated as the volume of a cylinder with equivalent diameter $D_{0}$ and overall length $L_{0}$. The following equation is applied [30,31]:

$$
q_{c}=\frac{V_{o}}{E} \frac{d p}{d t}
$$


where $p$ is the absolute pressure and $q_{c}$ indicates the volumetric flow rate through the chamber computed with reference to $\rho_{0}$. The actual bulk modulus $E$ is calculated as follows:

$$
E=E_{o} \frac{1+\varepsilon\left(\frac{p_{0}}{p}\right)^{1 / \gamma}}{1+\varepsilon \frac{p_{0}^{1 / \gamma}}{\gamma p^{(\gamma+1) / \gamma}} E_{o}},
$$

where $E_{0}$ is the pure liquid bulk modulus, $\gamma$ is the gas-specific heat ratio $(\gamma=1.4), \varepsilon$ is the relative gas content at atmospheric pressure and $p_{0}$ is the atmospheric pressure $[28,30]$.

The hydraulic part of the piezo-valve is simulated using the orifice Equation (1), in which the orifice area is evaluated as $A_{r}=\pi d x$, where $d$ is the diameter of the nozzle (10) and $x$ is the displacement of the ring bender with respect to the nozzle tip. The displacement $x$ of the ring bender is determined according to the equilibrium of the actuation force and the resistant forces acting on the closure system, as follows:

$$
F_{r b}+F_{\text {flow }}-m_{0} \ddot{x}-C_{r b} \dot{x}-k_{r b}\left(x+x_{0}\right)=0,
$$

where $F_{r b}$ denotes the force exerted by the ring bender having stiffness $k_{r b}, C_{r b}$ is the damping coefficient of the moving parts (ring bender, o-rings and closure member) having mass $m_{0}, x_{0}$ is the pre-compression obtained through the adjuster (9) and $F_{\text {flow }}$ is the flow force acting on the ring bender [28]. Considering that the flow exiting the piezo valve can be assumed radial, the flow forces acting on the ring bender can be estimated by the following simplified equation [28]:

$$
F_{\text {flow }}=\left(p_{7}-p_{T}\right) \frac{\Pi d^{2}}{4}
$$

where $p_{7}$ and $p_{T}$ are the absolute pressure at point (7) and the absolute discharge pressure, respectively.

The ring bender displacement is limited by two stops that restrict its motion between the upper and lower bounds. Each stop is represented as a spring combined with a damper. A force $F_{\text {stop }}$ acts on the ring bender when the maximum or minimum displacement is reached:

$$
\begin{aligned}
& F_{\text {stop }}=K_{\text {stop }}\left(x_{\text {max }}-x\right)+C_{\text {stop }} \frac{d}{d t}\left(x_{\text {max }}-x\right) \text { for } x \geq x_{\text {max }}, \\
& F_{\text {stop }}=K_{\text {stop }}\left(x_{\text {min }}-x\right)+C_{\text {stop }} \frac{d}{d t}\left(x_{\text {min }}-x\right) \text { for } x \leq x_{\text {min }},
\end{aligned}
$$

where $K_{\text {stop }}$ and $C_{\text {stop }}$ are the spring stiffness and damping of the stop, respectively, with $x_{\max }$ and $x_{\min }$ denoting the maximum and minimum displacement of the ring bender [30].

Piezoelectric hysteresis is considered by implementing the Bouc-Wen hysteresis model, described and used in [28]:

$$
\frac{d n}{d t}=\alpha d_{v} \frac{d V_{a m p}}{d t}-\beta\left|\frac{d V_{a m p}}{d t}\right| n-\delta \frac{d V_{a m p}}{d t}|n|,
$$

where $n$ is the hysteresis nonlinear term, $\alpha, \beta$ and $\delta$ are tuning parameters employed to match the hysteresis model to experimental data (the values from $[27,28]$ are used) and $V_{a m p}$ is the output voltage of the amplifier (ranging from $-100 \mathrm{~V}$ to $100 \mathrm{~V}$ ). The hysteresis non-linear term allows the force of the ring bender $F_{r b}$ to be expressed as a function of the output voltage of the amplifier, as follows:

$$
F_{r b}=K_{d, v}\left(V_{a m p}-n\right)
$$

where $K_{d, v}$ is the ring bender maximum force divided by the maximum operating voltage, which represents the ring bender conversion factor (namely, from amplified voltage to force). 
The amplifier is simulated by using a second order transfer function $[27,28]$ :

$$
V_{a m p}=\frac{K_{a} \omega_{n, 0}{ }^{2}}{s^{2}+2 \xi \omega_{n, 0} s+\omega_{n, 0}{ }^{2}} V_{c},
$$

where $V_{c}$ is the control voltage that is supplied to the amplifier (from $-5 \mathrm{~V}$ to $5 \mathrm{~V}$ ), $K_{a}$ is the gain of the amplifier $\left(K_{a}=20\right), \omega_{n, 0}$ is the natural frequency of the amplifier $\left(\omega_{n, 0}=1400 \mathrm{rad} / \mathrm{s}\right)$ and $\xi$ is the damping factor of the amplifier $(\xi=1.5)$. In addition, to model the current limit $\left(I_{\max }\right)$, the rate of change of the amplified voltage is limited according to the following equation $[27,28]$ :

$$
\frac{d V_{a m p}}{d t}=\frac{I_{m a x}}{C}
$$

where $C$ is the capacitance.

The simulations were performed using the values for the operating parameters reported in Table 2. Some of the parameters shown in Table 2 are known data (such as oil characteristics, supply and return pressure, length and diameter of the oil chamber, ring bender characteristics, diameter of the nozzle, mass of the moving parts, maximum current and capacitance of the amplifier). Other parameters were tuned to match the experimental results. Specifically, the restrictor areas have been tuned to obtain the same pressure drops, i.e., from the pump to point (5) and across the variable restrictor (6); the properties of the mechanical stops (stop damping coefficient and stop stiffness) have been tuned to obtain the same bouncing behaviour when the closure member hits the mechanical stops; finally, the amplifier parameters (natural frequency and damping factor) have been set to obtain the same transient as the measured amplified voltage. Concerning the discharge coefficients, their values have been set under the hypothesis of turbulent flow. The dynamic system was solved by computing its states at successive time steps over a specified time span. The time step was taken equal to $10^{-4} \mathrm{~s}$, in order to have a good accuracy.

\begin{tabular}{|c|c|c|c|}
\hline Component & Parameter & Symbol & Value \\
\hline \multirow{2}{*}{ Oil } & Density & $\rho_{0}$ & $851 \mathrm{~kg} / \mathrm{m}^{3}$ \\
\hline & Relative gas content & $\varepsilon$ & 0.01 \\
\hline \multirow{3}{*}{$\begin{array}{l}\text { Supply line (from } \\
\text { accumulator } 4 \text { to point 5) }\end{array}$} & Supply pressure & $p_{4}$ & $71 \mathrm{bar} / 51 \mathrm{bar}$ \\
\hline & Fictitious restriction area & $A_{r, 4-5}$ & $4 \mathrm{~mm}^{2}$ \\
\hline & Discharge coefficient & $C_{D, 4-5}$ & 0.7 \\
\hline \multirow{2}{*}{ Variable restrictor (6) } & Restriction area & $A_{r, 6}$ & $0.42 \mathrm{~mm}^{2}$ \\
\hline & Discharge coefficient & $C_{D, 6}$ & 0.7 \\
\hline \multirow{2}{*}{$\begin{array}{l}\text { Oil chamber volume (from } \\
\text { restriction } 6 \text { to nozzle } 10 \text { ) }\end{array}$} & Equivalent diameter & $D_{o}$ & $20 \mathrm{~mm}$ \\
\hline & Equivalent length & $L_{o}$ & $60 \mathrm{~mm}$ \\
\hline \multirow{11}{*}{ Piezo valve } & $\begin{array}{l}\text { Ring bender conversion factor (force } \\
\text { over voltage) }\end{array}$ & $K_{d, v}$ & $0.13 \mathrm{~N} / \mathrm{V}$ \\
\hline & Diameter of the nozzle (10) & $d$ & $1 \mathrm{~mm}$ \\
\hline & Discharge coefficient & $C_{D, v}$ & 0.65 \\
\hline & Mass of the moving parts & $m_{0}$ & $90 \mathrm{~g}$ \\
\hline & Damping coefficient & $C_{r b}$ & $26 \mathrm{Ns} / \mathrm{m}$ \\
\hline & Ring bender stiffness & $k_{r b}$ & $70,000 \mathrm{~N} / \mathrm{m}$ \\
\hline & Pre-compression of the ring bender & $x_{0}$ & $50 \mu \mathrm{m}$ \\
\hline & Stop damping coefficient & $C_{\text {stop }}$ & $500 \mathrm{Ns} / \mathrm{m}$ \\
\hline & Stop stiffness & $K_{\text {stop }}$ & $10^{7} \mathrm{~N} / \mathrm{m}$ \\
\hline & Maximum displacement of the ring bender & $x_{\max }$ & None \\
\hline & Minimum displacement of the ring bender & $x_{\min }$ & 0 \\
\hline Discharge line & Pressure & $p_{T}$ & 1 bar \\
\hline \multirow{5}{*}{ Amplifier } & Natural frequency & $\omega_{n, 0}$ & $1400 \mathrm{rad} / \mathrm{s}$ \\
\hline & Damping factor & $\xi$ & 1.5 \\
\hline & Maximum current & $I_{\max }$ & $1 \mathrm{~A}$ \\
\hline & Capacitance & C & $2 \times 1740 \mathrm{nF}$ \\
\hline & Gain of the amplifier & $K_{a}$ & 20 \\
\hline
\end{tabular}

Table 2. Parameters assumed for the simulations. 


\section{Results}

In this section, the experimental results are discussed and compared with the numerical predictions in order to provide a validation of the numerical model.

Afterwards, the validated numerical model is used to show that, by acting on some geometrical parameters, the performance of the proposed piezovalve can be enhanced.

\subsection{Experimental Results and Comparison with the Numerical Model}

Tests were performed on the test rig shown in Figure 3. Some of the more significant experimental results are here commented upon and compared with the numerical predictions obtained with the numerical model described in Section 2.3. For the sake of clarity, the tests presented here are named test 1 , test 2 , test 3 , test 4 and test 5 . The symbolism used in this section refers to the test rig representation of Figure 3.

The first experimental test (test 1 ) was performed with atmospheric pressure inside the valve and with the adjusters (9) and (15) being kept far from the closure member (11) in order to observe the behaviour of the ring bender without mechanical stops and with no pressure. An input sine voltage having $5 \mathrm{~V}$ amplitude and $1 \mathrm{~Hz}$ frequency was delivered to the amplifier, which transformed this signal into a high voltage signal having $100 \mathrm{~V}$ amplitude with the same frequency.

Figure 5 a provides the measured amplified voltage (blue line) and the numerical one (red curve) together with the input voltage (black line), showing that there is a very good agreement between the numerical prediction and the experimental value.

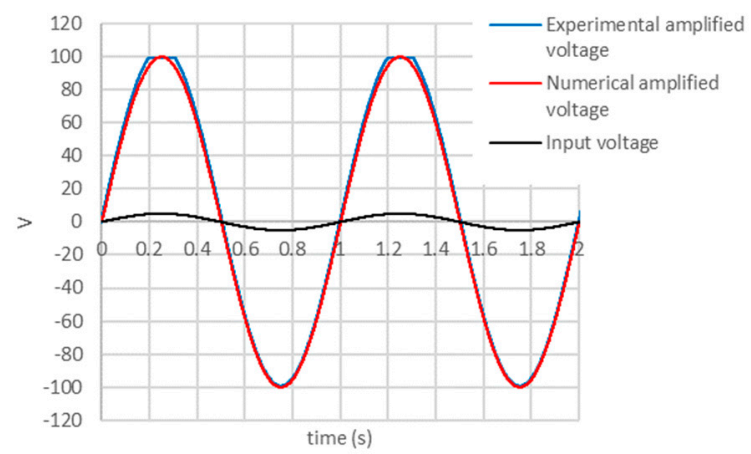

(a)

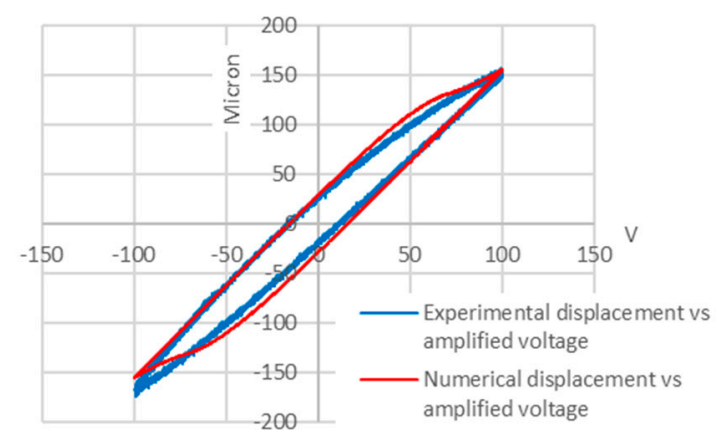

(b)

Figure 5. Test 1. Comparison between measured amplified voltage and simulated one for a sine wave control voltage (input voltage to the amplifier) having $5 \mathrm{~V}$ amplitude and $1 \mathrm{~Hz}$ frequency: (a); corresponding plots of the displacement of the ring bender vs. amplified voltage with atmospheric pressure inside the valve: (b).

The amplified voltage of Figure 5a applied to the ring bender caused the latter to move inside the valve case without mechanical stops, thus reaching the maximum displacement in both directions. Figure $5 \mathrm{~b}$ reports the amplified voltage on the $\mathrm{x}$ axis and the corresponding ring bender displacement on the y axis. The blue curve refers to the experimental data and the red curve to the numerical results. In this test, the displacement is measured from the neutral position of the ring bender when no voltage is applied. Figure $5 \mathrm{~b}$ clearly shows the hysteresis of the ring bender: for a given value of the amplified voltage, two values of the displacement are possible, depending on the history of the displacement. It is noteworthy that the model employed for the simulation of the hysteresis is reliable, providing, overall, a good correspondence with the experimental hysteresis.

After this preliminary test focused on the hysteresis, step tests were performed, with the oil temperature being kept around $50{ }^{\circ} \mathrm{C}$. These tests consisted in sending a step voltage to the amplifier, which, in turn, sent a corresponding amplified step voltage to the ring bender. The resulting 
displacement of the ring bender was measured along with the pressure at points (5) and (7) of Figure 3 . In these tests, the displacement of the ring bender is measured from the nozzle tip (10).

In the first of the step tests considered in this analysis (here denoted by "test 2"), the supply (absolute) pressure was kept equal to 71 bar (namely, 70 bar relative), and the absolute pressure at the outlet of the valve was about 1 bar. The ring bender was pre-compressed with $x_{0}=50 \mu \mathrm{m}$ by acting on the adjuster (9); instead, the other adjuster (15) was kept far from the closure member, so that no mechanical stop was imposed to the maximum opening of the ring bender. The control voltage (input voltage from the PC to the amplifier) was changed from $-5 \mathrm{~V}$ to $+5 \mathrm{~V}$, which produced an amplified voltage step from $-100 \mathrm{~V}$ to $+100 \mathrm{~V}$. Figure $6 \mathrm{a}$ shows the control signal (black line) and the amplified voltage (orange dashed line) measured during this test; the simulated amplified voltage is also plotted as a green dashed line. The good correspondence between the experimental amplified voltage and the numerical one demonstrates, once more, the good accuracy achieved with the numerical model and the good choice of the parameters used for the simulation of the amplifier (see Table 2).

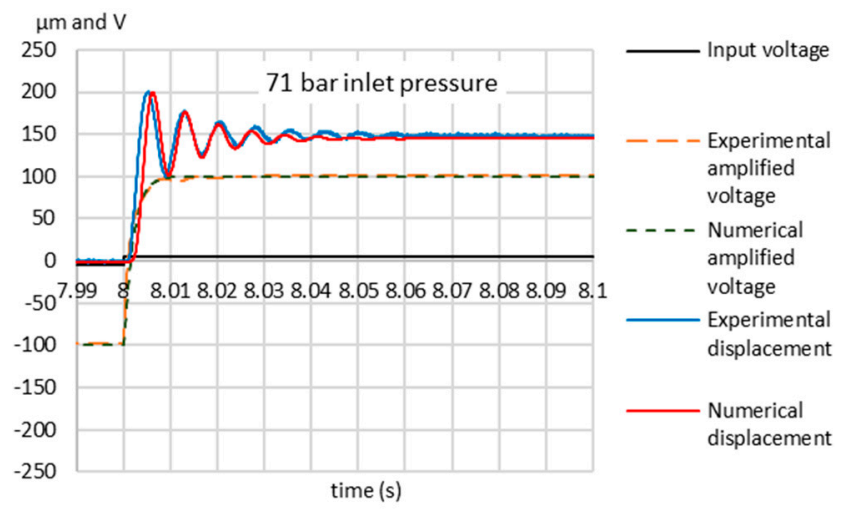

(a)

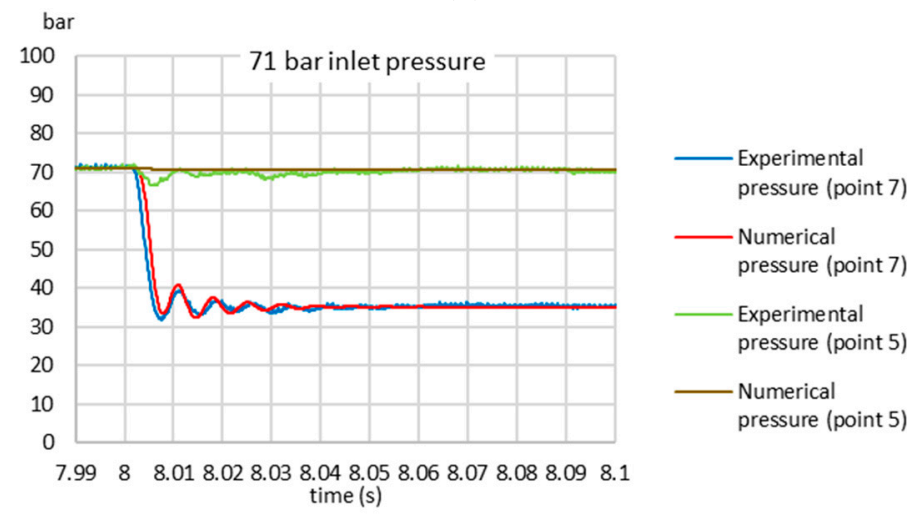

(b)

Figure 6. Test 2 (71 bar supply pressure). Comparison between measured amplified voltage and simulated one and between measured displacement and simulated one for a positive step control voltage (input voltage to the amplifier) from $-5 \mathrm{~V}$ to $+5 \mathrm{~V}$ : (a); comparison between measured pressures and simulated ones: $(\mathbf{b})$.

Figure 6 a also shows the displacement of the ring bender experimentally measured during "test 2" (blue curve); correspondingly, the simulated displacement is plotted as a red curve. When $-100 \mathrm{~V}$ was applied to the ring bender, the latter applied a blocking force of about $-13 \mathrm{~N}$ to the nozzle (10) without moving (because it was pre-compressed). In contrast, when $+100 \mathrm{~V}$ was applied, the ring bender moved from the nozzle, thus opening the valve with a force of about $+13 \mathrm{~N}$. One can observe that the simulated displacement matches the experimental one; this very good agreement confirms the reliability of the numerical model. Moreover, Figure 6a shows that, because there is not a mechanical 
stop in the opening direction, the ring bender oscillates producing overshoots and undershoots until reaching a stable position. Finally, one can notice that the rise time is very fast, since the time required for the displacement to rise from $10 \%$ to $90 \%$ of its final value is less than $5 \mathrm{~ms}$.

Figure $6 \mathrm{~b}$ shows the comparison among the experimental pressures at points (5) and (7) and the corresponding numerical predictions, regarding "test 2". As shown by this graph, the initial pressures measured at point (5) and point (7) were the same, namely, 71 bar, because the valve was initially closed by the ring bender. When the ring bender opened the valve, the pressure at port (7) very quickly decreased down to about a half of the supply pressure (this pressure drop was achieved by adjusting the variable restrictor (6)), reaching $90 \%$ of the minimum value within $5 \mathrm{~ms}$. The comparison between the experimental data and numerical predictions is very good, especially concerning the pressure at point (7). With regard to the pressure at point (5), the numerical model is not able to reproduce the oscillations present in the experimental signal; this might be due to inertia effects of the oil comprised between the supply line and point (5). However, what is important in this analysis is the good prediction of the pressure at point (7), because this pressure signal is the one to be used for the control of the main spool.

A second step test is now described; this test, to be referred to as "test 3 ", is the continuation of "test 2 ", in that, after reaching the maximum opening shown in Figure $6 \mathrm{a}$, the valve was closed by changing the input signal to the amplifier from $+5 \mathrm{~V}$ to $-5 \mathrm{~V}$. The amplified voltages (experimental data corresponding to the orange dashed line; numerical data corresponding to the green dashed line) are reported in Figure 7a. Again, there is a good agreement between the experimental measurement and the numerical predictions in terms of amplified voltage, even though a slight delay is noticed in the experimental signal when the amplified voltage is approaching the minimum value $(-100 \mathrm{~V})$. However, this effect can be considered negligible since both the experimental and the numerical voltage reach a very high level of amplification (i.e., about $-90 \mathrm{~V}$ ) at the same time, which corresponds to a very high level of force (namely, about $-12 \mathrm{~N}$ ).

Figure 7a also shows the comparison between the experimental displacement obtained in "test 3" (blue curve) and the corresponding numerical one (red curve): this graph again confirms the reliability of the numerical model, given the very good agreement between the two curves. Moreover, the very good performance of the valve is again proved by the very short time taken by the ring bender to close the valve (less than $5 \mathrm{~ms}$ ). In this case, no oscillations are present, because the nozzle (10) acts as a mechanical stop for the ring bender. In contrast, one can observe that the ring bender bounces back after hitting the nozzle; overall, this bouncing behaviour is well reproduced by the simplified Equation (6b).

Figure $7 \mathrm{~b}$ shows the pressure trends measured and predicted at points (5) and (7) in "test 3". In addition to noticing, once again, the good accuracy of the numerical model, one can notice that the ring bender perfectly achieves its task, namely, it fully closes the valve, and the pressure at point (7) is brought back to its initial value of 71 bar very quickly. Because this pressure level is maintained over time, this means that the quiescent flow is negligible, thus achieving the main goal of this work, namely, a remarkable reduction of the overall internal leakage.

The same tests as those shown in Figures 6 and 7 were done for a different inlet pressure, namely, 51 bar. In particular, Figure 8 shows the step test performed with an amplified voltage step from $-100 \mathrm{~V}$ to $+100 \mathrm{~V}$ for a supply pressure of 51 bar, to be referred to as "test 4 "; instead, Figure 9 shows the step test performed with an amplified voltage step from $+100 \mathrm{~V}$ to $-100 \mathrm{~V}$ for a supply pressure of 51 bar, to be referred to as "test 5 ". The graphs again show the comparison between experimental data and numerical predictions in terms of amplified voltage, ring bender displacement and pressures at points (5) and (7). 


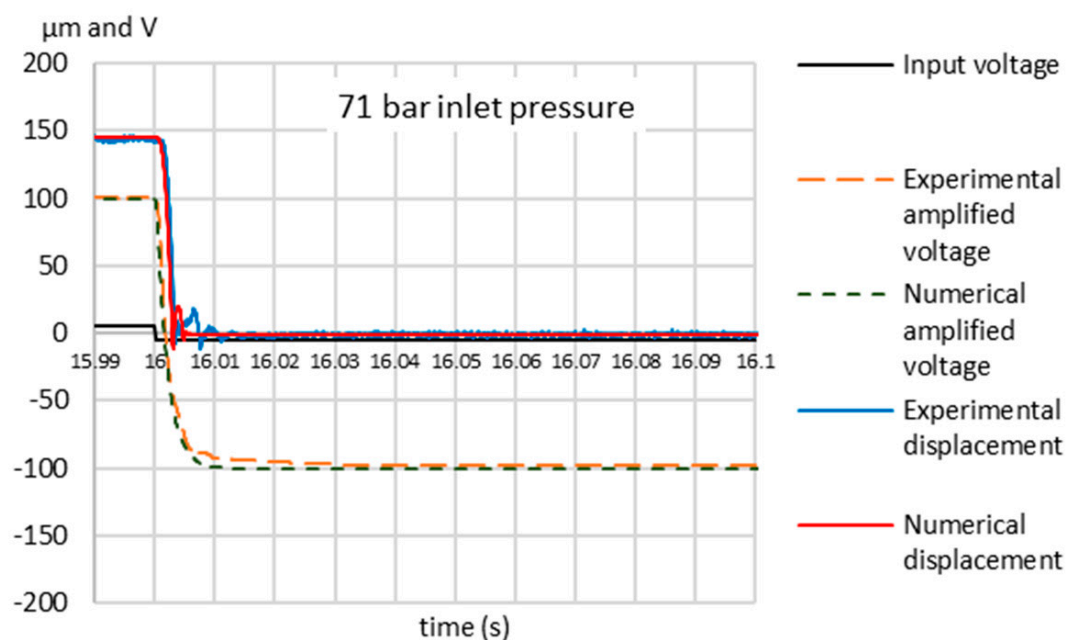

(a)

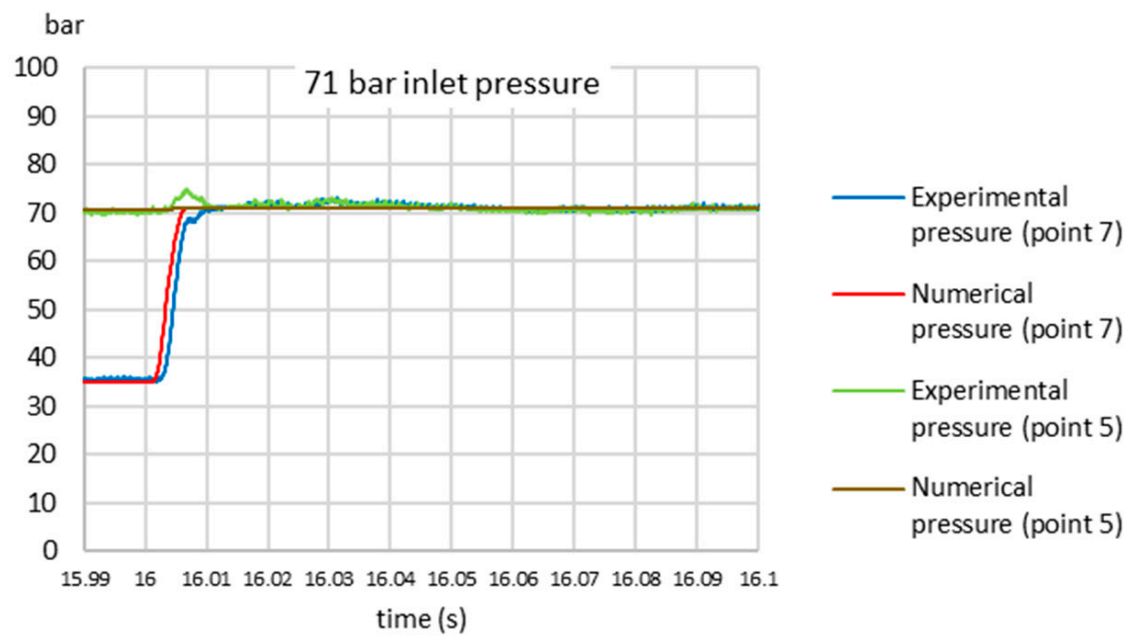

(b)

Figure 7. Test 3 (71 bar supply pressure). Comparison between measured amplified voltage and simulated one and between measured displacement and simulated one for a negative step control voltage (input voltage to the amplifier) from $+5 \mathrm{~V}$ to $-5 \mathrm{~V}$ : (a); comparison between measured pressures and simulated ones: (b).

The graphs of Figures 8 and 9 confirm both the high accuracy of the numerical model and the very fast response of the valve. The comparison between Figures $6 \mathrm{a}$ and $8 \mathrm{a}$ shows that the ring bender reached a higher displacement, namely, about 150 micron, for 71 bar inlet pressure, whereas about 140 micron was reached for 51 bar inlet pressure. This is due to the fact that the higher pressure acting on the nozzle causes a greater flow force pushing the ring bender in the opening direction, according to Equations (6a) and (6b).

It is noteworthy that, with respect to the experimental data, the numerical model slightly advances the pressure rise at point (7) when the valve is closed; conversely, it slightly delays the pressure drop at point (7) when the valve is opened. However, in both cases, this difference is very low, being of the order of $1 \mathrm{~ms}$. Moreover, these two effects compensate each other, therefore, the numerical model is capable of providing a good overall prediction of the valve performance. The difference between the experimental data and numerical predictions can be attributed to the assumed model of the hysteresis of the ring bender and to the hypothesis of neglecting, in the numerical model, the elasticity of the hoses employed in the experimental set-up. 


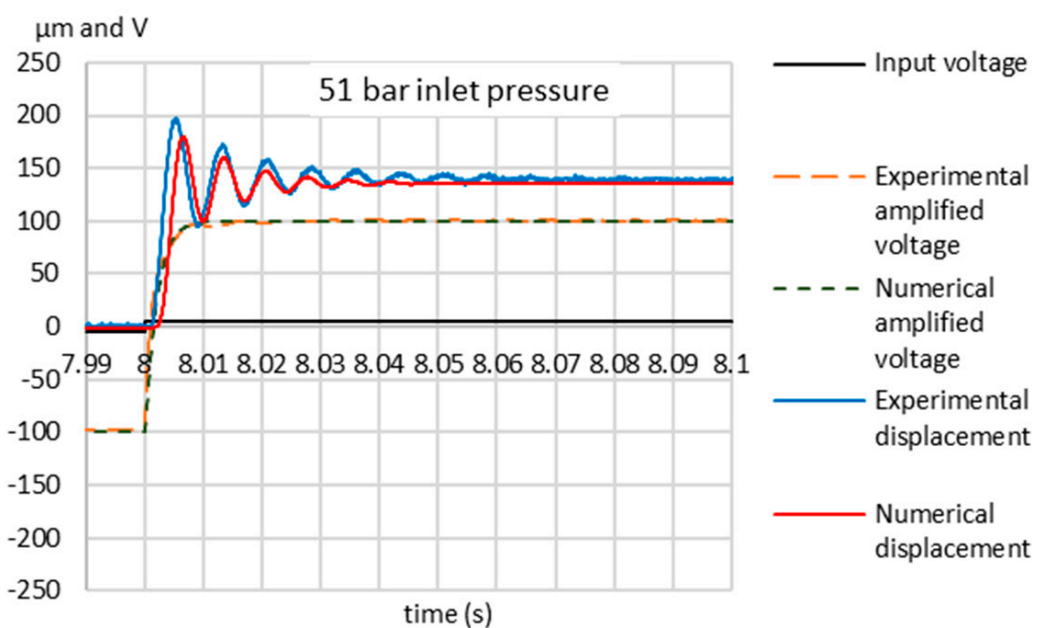

(a)

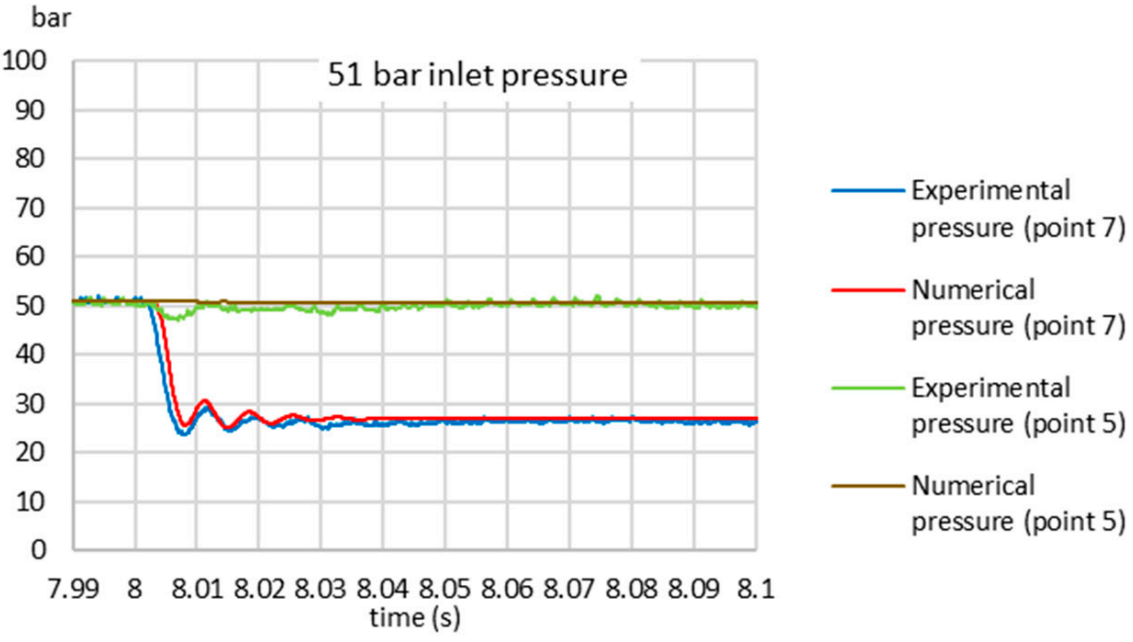

(b)

Figure 8. Test 4 (51 bar supply pressure). Comparison between measured amplified voltage and simulated one and between measured displacement and simulated one for a positive step control voltage (input voltage to the amplifier) from $-5 \mathrm{~V}$ to $+5 \mathrm{~V}$ : (a); comparison between measured pressures and simulated ones: (b).

Finally, Figure 10 shows, on the same graph, the displacement and the pressure at point (7) measured during repeated opening and closing procedures of the valve, for a supply pressure of 71 bar. This graph is instrumental in pointing out that, when the valve is closed, the pressure at point (7) is constant and equal to the supply pressure over time. This confirms that the quiescent flow (internal leakage) is negligible when the valve is closed, otherwise a pressure decrease would be noticed at point (7). 


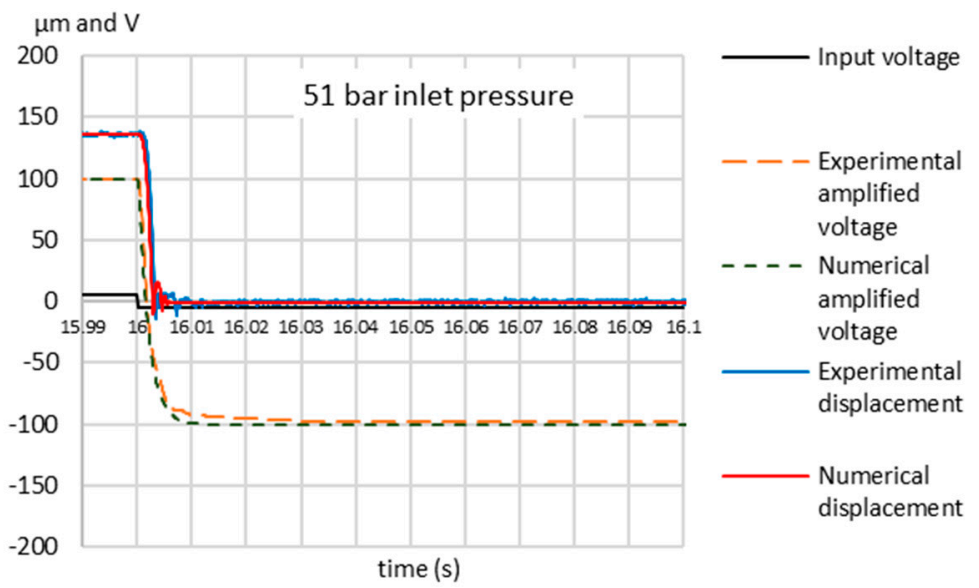

(a)

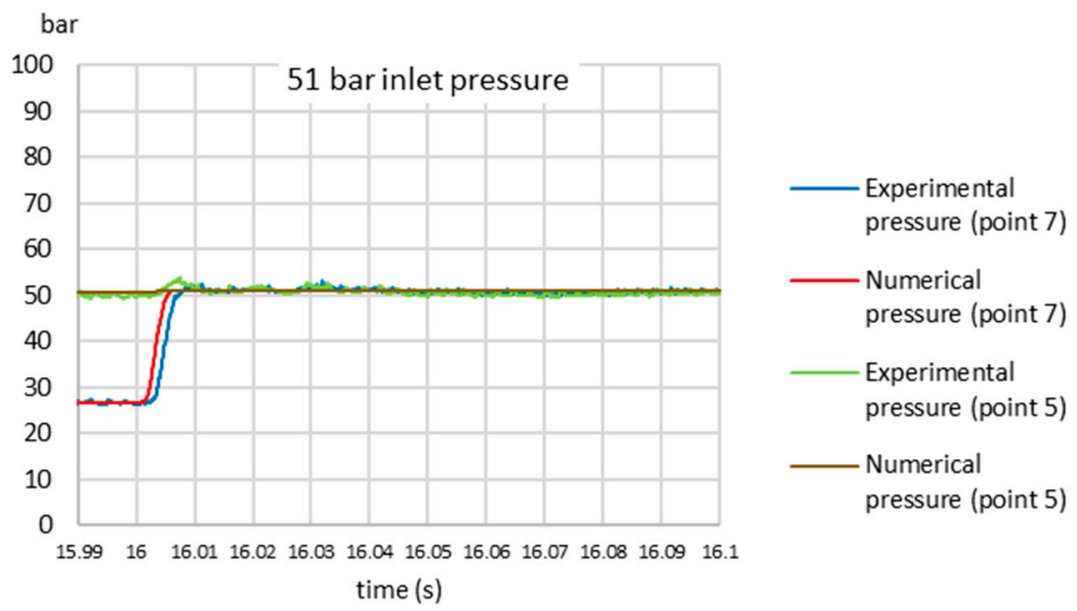

(b)

Figure 9. Test 5 (51 bar supply pressure). Comparison between measured amplified voltage and simulated one and between measured displacement and simulated one for a negative step control voltage (input voltage to the amplifier) from $+5 \mathrm{~V}$ to $-5 \mathrm{~V}$ : (a); comparison between measured pressures and simulated ones: (b).

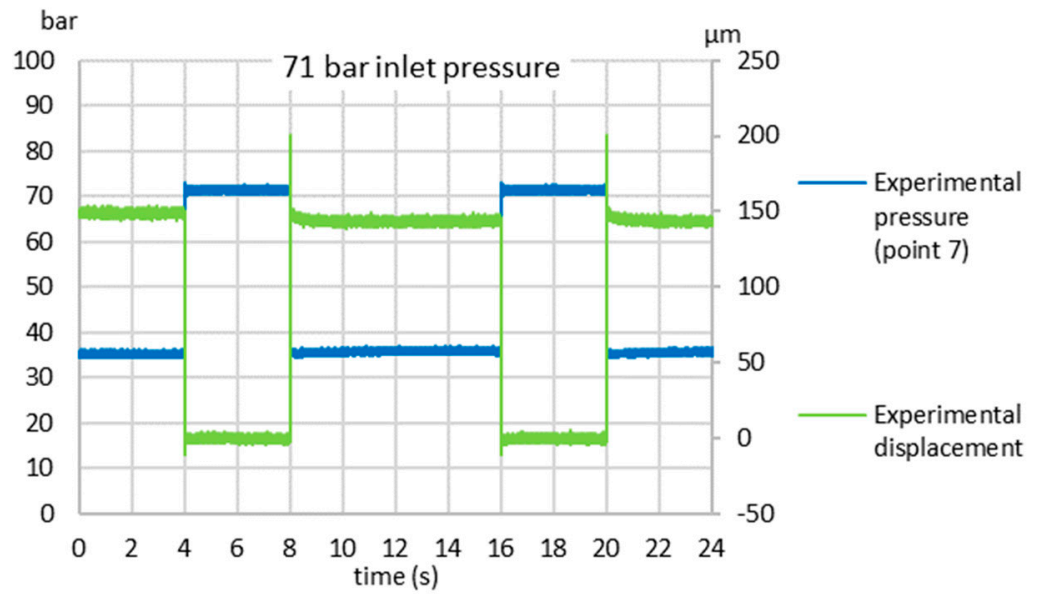

Figure 10. Pressure at point (7) and displacement measured during repeated opening and closing procedures of the piezo-valve. 


\subsection{Numerical Analysis of the Piezo-Valve}

A numerical analysis is provided in this section to prove that, by properly acting on some geometrical parameters, the valve concept can be profitably applied for the control of a main stage spool valve. To this end, the effects of some geometrical parameters are considered, and the results are critically discussed. Again, the symbolism used in this section refers to the test rig representation of Figure 3.

At first, the effects of the volume of the chamber comprised between the restrictor (6) and the nozzle (10) are assessed. As already mentioned, in the experimental prototype, this volume is equivalent to a cylinder having a diameter $D_{0} \simeq 20 \mathrm{~mm}$ and a length $L_{0} \simeq 60 \mathrm{~mm}$. Instead, in commercially available two stage servovalves, this volume is much lower to ensure fast response of the main spool. To assess the effects of reducing this volume, this analysis considers five cylindrical volumes, having diameters $D=K D_{0}$ and lengths $L=K L_{0}$, with $K=1,0.8,0.6,0.4,0.2$. The five cases are here compared in terms of simulated displacement of the ring bender and pressure at point (7), since these parameters are representative of the valve performance.

Figure 11a shows the ring bender displacement simulated for $D=K D_{0}$ and $L=K L_{0}$, with $K=1$, $0.8,0.6,0.4,0.2$ and for an amplified step voltage from $-100 \mathrm{~V}$ to $+100 \mathrm{~V}$ (supply pressure $=71 \mathrm{bar}$ ). It is noteworthy that the reduction of the volume causes a reduction of the oscillations; however, for $K=0.4$ and $K=0.2$, the simulated trends of the displacement are very similar, which means that a further reduction of the volume will barely change the results. The effects of the volume reduction are also important in terms of the pressure drop at point (7): as shown in Figure 11b, smaller oil volumes cause the pressure to drop more quickly. This is particularly important for the actuation of a main spool: by reducing the oil volume in the system, the pressure at the spool ends will change more quickly, and the performance of the valve will be enhanced.
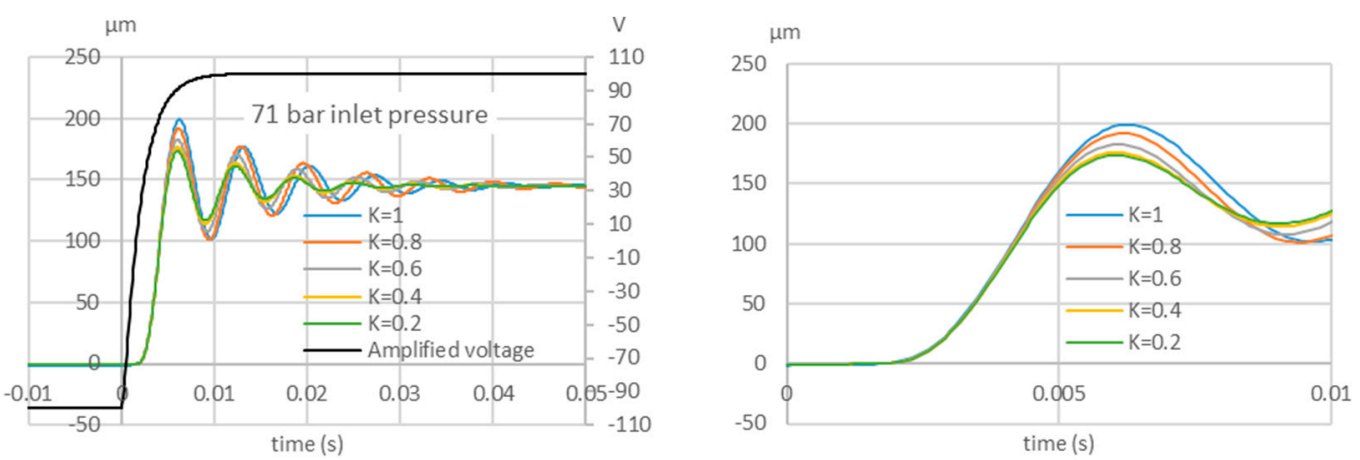

(a)
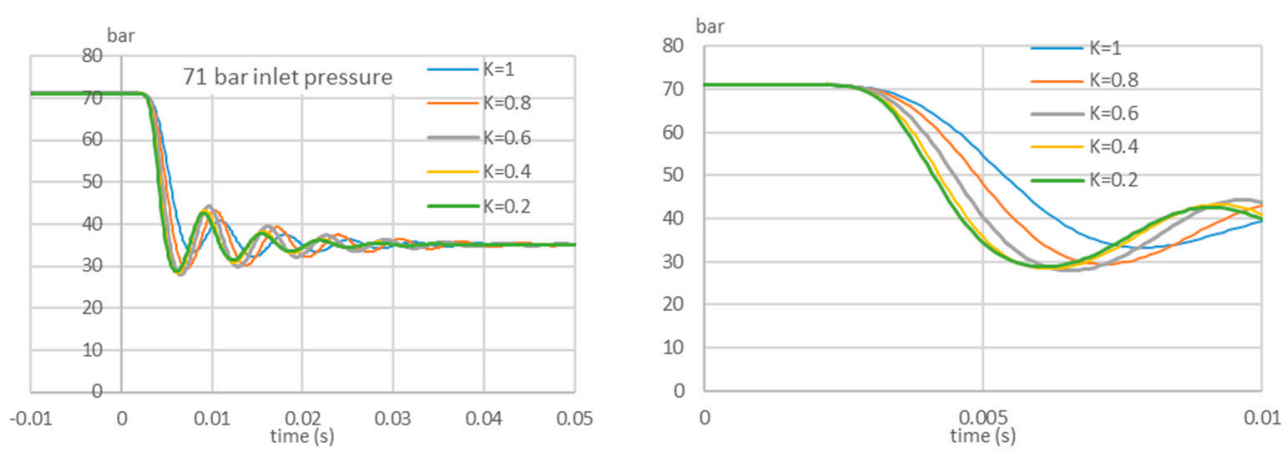

(b)

Figure 11. Ring bender displacement with enlargement (a) and pressure at point 7 with enlargement (b), simulated for an amplified voltage from $-100 \mathrm{~V}$ to $+100 \mathrm{~V}$ and for different volumes of the chamber comprised between the restriction (6) and the nozzle (10), having diameter $D=K D_{0}$ and length $L=K$ $L_{0}$, with $K=1,0.8,0.6,0.4,0.2$ (supply pressure $=71$ bar). 
Similarly, Figure 12a shows the ring bender displacement simulated for $D=K D_{0}$ and $L=K$ $L_{0}$, with $K=1,0.8,0.6,0.4,0.2$, for a negative amplified voltage step from $+100 \mathrm{~V}$ to $-100 \mathrm{~V}$. In contrast to the previous case (positive voltage step from $-100 \mathrm{~V}$ to $+100 \mathrm{~V}$ ), the simulated trends of the displacement are almost identical, which means that the change in the volume does not affect the displacement. However, as shown in Figure 12b, the change in volume has a remarkable effect on the pressure rise at point (7), because lower volumes cause the compressibility effects to be less important. For this reason, it is important to reduce the volume of the chamber comprised between the variable restrictor (6) and the valve nozzle (10) to improve the performance of the valve. However, also in this case, the difference between $\mathrm{k}=0.2$ and $\mathrm{k}=0.4$ is almost negligible, so that a further reduction of the volume will be unimportant.
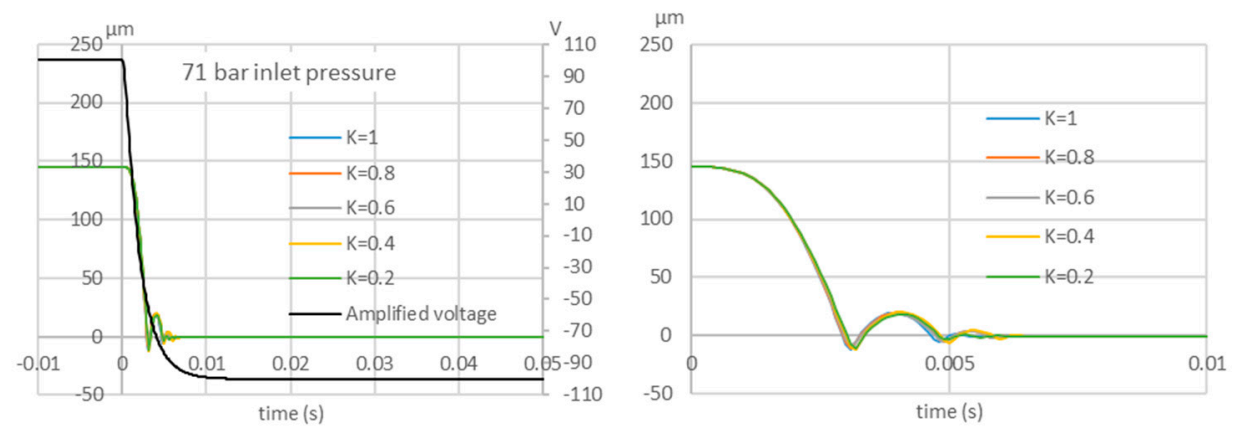

(a)
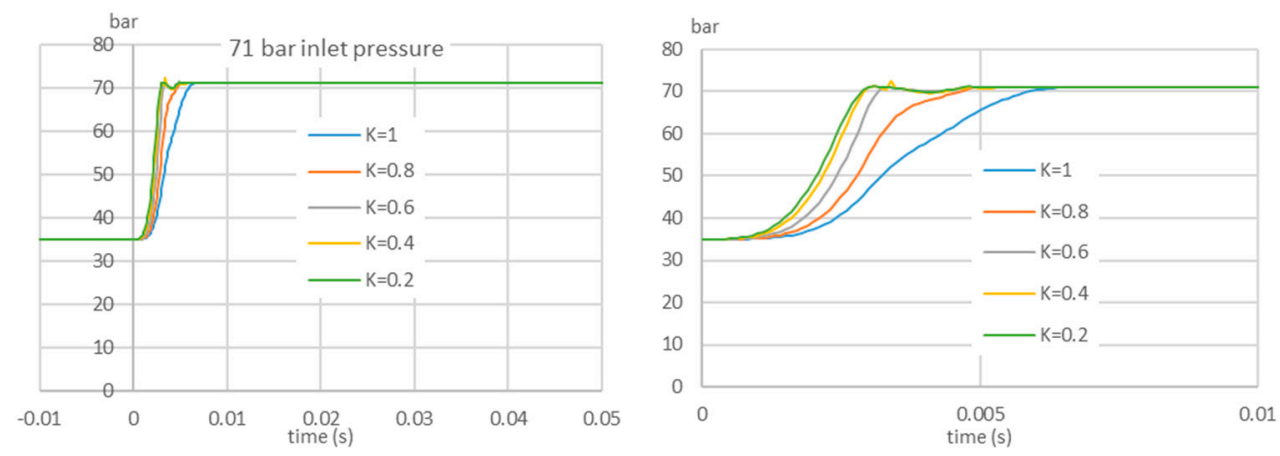

(b)

Figure 12. Ring bender displacement with enlargement (a) and pressure at point 7 with enlargement (b), simulated for an amplified voltage from $+100 \mathrm{~V}$ to $-100 \mathrm{~V}$ and for different volumes of the chamber comprised between the restriction (6) and the nozzle (10), having diameter $D=K D_{0}$ and length $L=K$ $L_{0}$, with $K=1,0.8,0.6,0.4,0.2$ (supply pressure $=71$ bar).

Another parameter that can be optimised to further improve the performance of the valve is the mass of the moving parts. In the prototype, this mass was about $90 \mathrm{~g}$, mainly due to the material and geometry of the closure member, which also comprised a nut. A reduction of the dimensions and weight of the closure member would not be a difficult task for an optimised implementation of this novel architecture. Therefore, to assess the effects of this parameter, this analysis considers five values for the mass, namely, $m=K m_{0}$, with $K=1,0.8,0.6,0.4,0.2$ (with $m_{0}$ denoting the mass of the prototype). The diameter and length of the volume comprised between the restriction (6) and the nozzle (10) are taken equal to $D=0.6 D_{0}$ and $L=0.6 L_{0}$. The five cases are again compared in terms of simulated displacement of the ring bender and pressure at point (7).

Figure 13a shows the different trends of the displacement simulated for $m=K m_{0}$, with $K=1,0.8$, $0.6,0.4,0.2$ and for a positive amplified step voltage from $-100 \mathrm{~V}$ to $+100 \mathrm{~V}$. It is noteworthy that the 
oscillations around the set point are remarkably reduced by reducing the mass of the moving parts. Moreover, lower values of the mass slightly increase the slope of the transient curve due to the lower inertia; as a result, a lower mass allows the maximum displacement to be stably reached in a shorter time. The beneficial effect of reducing the mass of the moving parts is also evident by analysing the simulated pressure drop at point (7), as shown in Figure 13b. It can be noticed that lower values of the mass make the pressure reach a stable value more quickly than higher values of the mass.
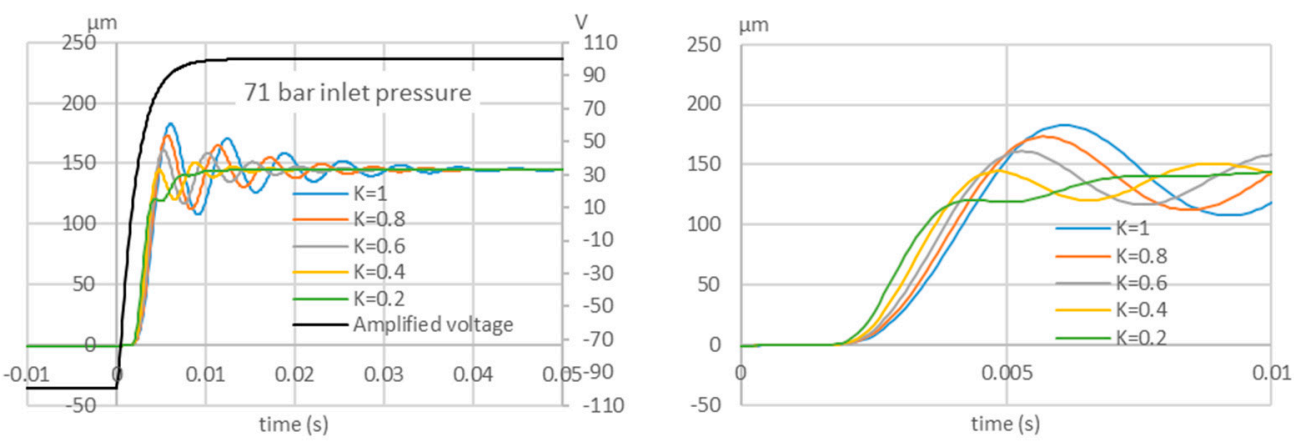

(a)
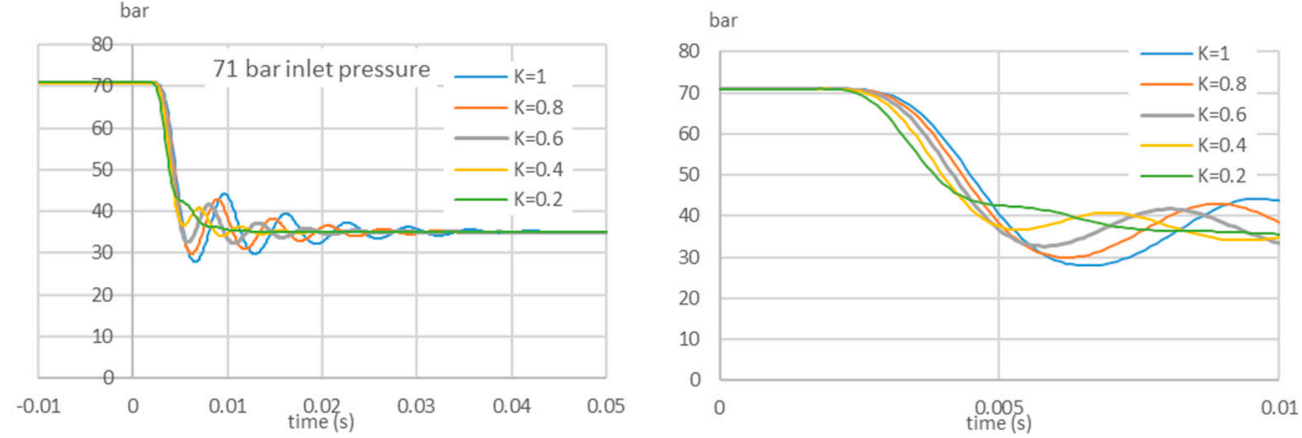

(b)

Figure 13. Ring bender displacement with enlargement (a) and pressure at point 7 with enlargement (b), simulated for an amplified voltage from $-100 \mathrm{~V}$ to $+100 \mathrm{~V}$ and for different values of the mass of the moving parts: $m=K m_{0}$, with $K=1,0.8,0.6,0.4,0.2$ (supply pressure $=71$ bar, $D=0.6 D_{0}$ and $\left.L=0.6 L_{0}\right)$.

Similarly, Figure 14a shows the ring bender displacement simulated for $m=K m_{0}$, with $K=1$, $0.8,0.6,0.4,0.2$, for a negative amplified voltage step from $+100 \mathrm{~V}$ to $-100 \mathrm{~V}$. A difference is noticed in the final part of these curves. Indeed, a lower mass causes the ring bender to bounce back with lower intensity after hitting the nozzle and to provide a slightly faster response due to the lower inertia. Moreover, Figure 14b shows that lower values of the mass cause the pressure at point (7) to increase slightly faster. 

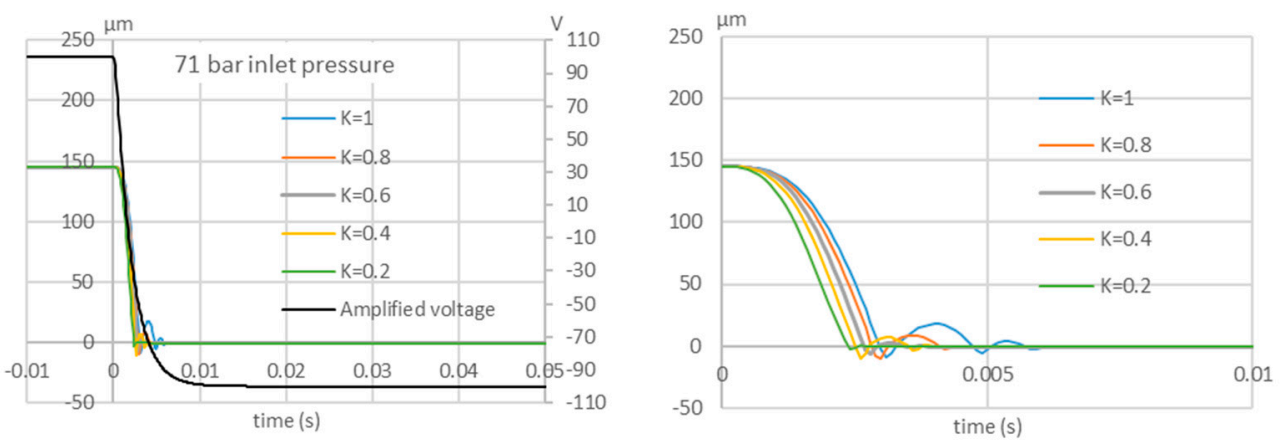

(a)
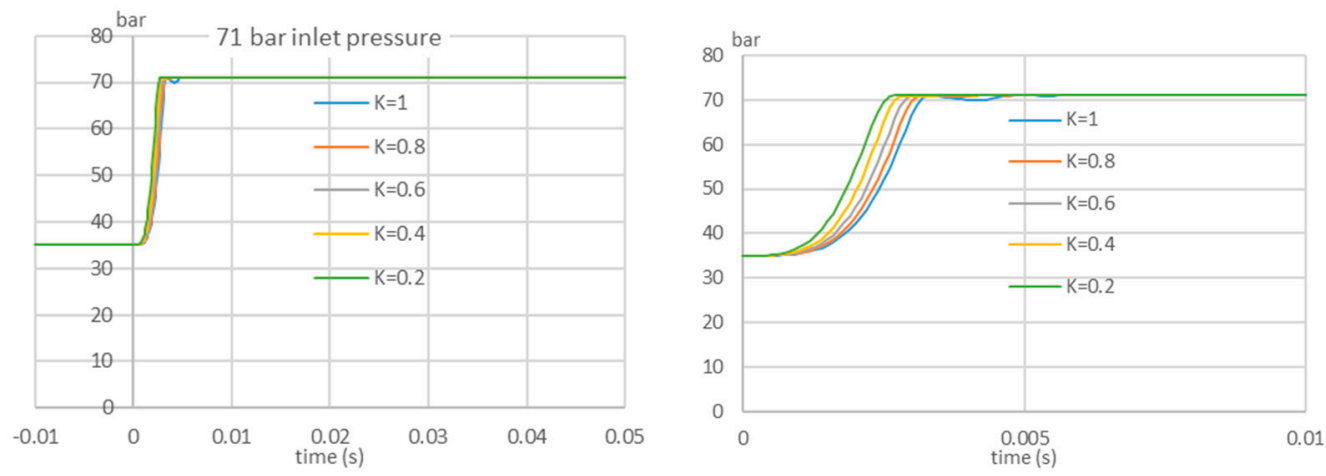

(b)

Figure 14. Ring bender displacement with enlargement (a) and pressure at point 7 with enlargement (b), simulated for an amplified voltage from $-100 \mathrm{~V}$ to $+100 \mathrm{~V}$ and for different values of the mass of the moving parts: $m=K m_{0}$, with $K=1,0.8,0.6,0.4,0.2$ (supply pressure $=71$ bar, $D=0.6 D_{0}$ and $\left.L=0.6 L_{0}\right)$.

In conclusion, the effects of the mass reduction of the moving parts can be beneficial for the valve performance, especially during the opening phase of the ring bender, because oscillations can be reduced and the stable maximum opening can be reached more quickly.

As a final analysis, the effects of the amplifier characteristics on the performance of the piezo-valve are investigated. Specifically, different values of the natural frequency of the amplifier are considered, namely, $\omega_{n}=\mathrm{k} \omega_{n, o}$ with $K=1,1.2,1.4,1.6,1.8$ and $\omega_{n, 0}=1400 \mathrm{rad} / \mathrm{s}$ (which is the natural frequency of the amplifier employed in the experimental activity). In this analysis, the diameter and length of the volume comprised between the restriction (6) and the nozzle (10) are taken equal to $D=0.6 D_{0}$ and $L=0.6 L_{0}$, while the mass is taken equal to $m=0.6 \mathrm{~m}_{0}$. Figure 15a shows the obtained trends of the amplified voltage (from $-100 \mathrm{~V}$ to $+100 \mathrm{~V}$ ) and of the displacement. These graphs reveal that the increase in the natural frequency causes a faster rise of the amplified voltage and, as a result, a faster ring bender displacement. Because of this, the pressure at point (7) decreases more quickly for higher values of the natural frequency, as shown in Figure 15b. 

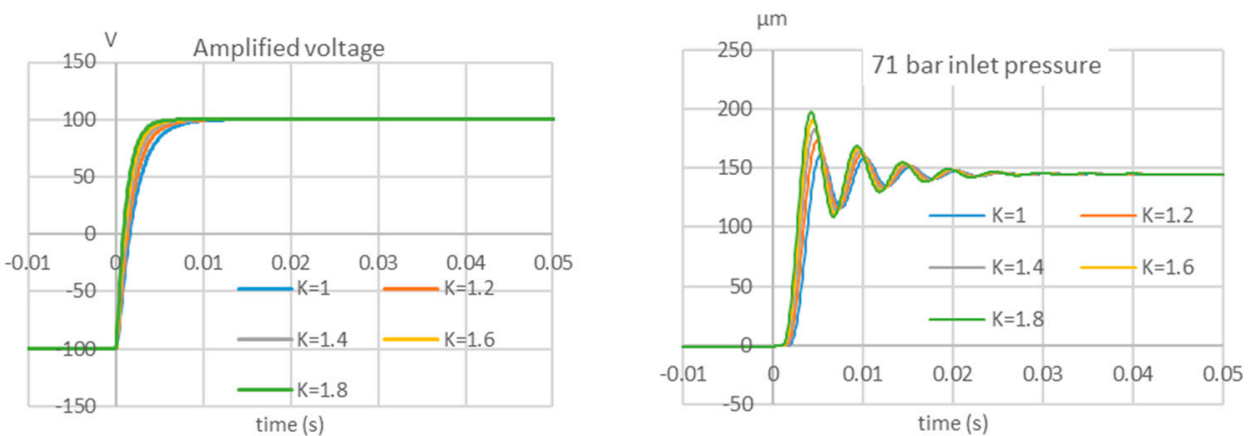

(a)
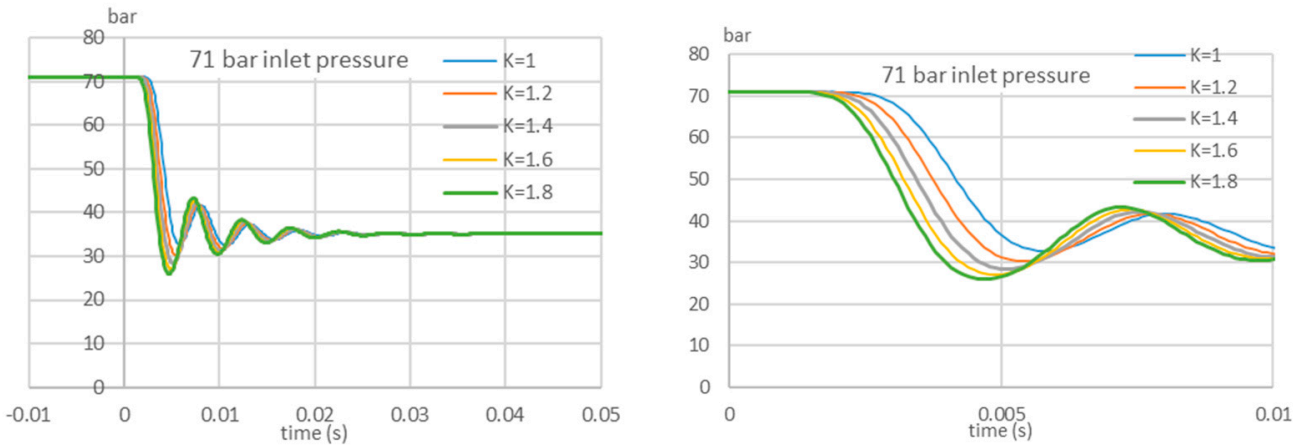

(b)

Figure 15. Amplified voltage and ring bender displacement (a) and pressure at point 7 with enlargement (b), simulated for an amplified voltage from $-100 \mathrm{~V}$ to $+100 \mathrm{~V}$ and for different values of the natural frequency of the amplifier: $\omega_{n}=\mathrm{k} \omega_{n, o}$ with $K=1,1.2,1.4,1.6,1.8$ (supply pressure $=71 \mathrm{bar}, D=0.6 D_{0}$ and $\left.L=0.6 L_{0}, m=0.6 m_{0}\right)$.

Similarly, Figure 16a shows the amplified voltage and the ring bender displacement simulated for $\omega_{n}=\mathrm{k} \omega_{n, 0}$ with $K=1,1.2,1.4,1.6,1.8$, but, in this case, for a negative amplified voltage step from $+100 \mathrm{~V}$ to $-100 \mathrm{~V}$. Again, faster amplified voltage trends are predicted for higher values of the natural frequency; instead, in terms of displacement and pressure rise, there is only a slight improvement for higher values of the natural frequency.

Overall, this numerical analysis has shown that the valve performance can be enhanced by reducing the volume of oil in the system, by reducing the mass of the moving parts and by increasing the natural frequency of the amplifier. In these conditions, the response time of the valve is very fast, with less than $5 \mathrm{~ms}$ being needed to fully close and open the valve.

This response time is comparable with commercially available pilot stages, but with the advantage of having minimised the quiescent flow needed for the valve operation. This represents a huge improvement in terms of power consumption, because, with the proposed configuration, the quiescent flow is negligible when the valve is at rest (namely, when the main spool is in the central position). The power consumption, avoided with the proposed solution when the valve is at rest, can be estimated as follows:

$$
P_{a}=\frac{q_{f}\left(p_{p}-p_{T}\right)}{\eta_{p}}
$$

where $q_{f}$ is the quiescent flow in the pilot stage of commercially available units (see Figure 1), $p_{p}$ and $p_{T}$ are the supply and discharge pressure, respectively, and $\eta_{p}$ is the pump efficiency. In order to estimate the power consumption, reference values can be used. For example, for an inlet pressure $p_{p}=70$ bar, the quiescent flow in commercially available units can be as high as $q_{f}=0.43 \mathrm{l} / \mathrm{min}$ (as occurs in Moog type 30 series 35 double nozzle-flapper servovalves [2,32]). Instead, for an inlet 
pressure $p_{p}=210$ bar, the quiescent flow in commercially available units can be increased up to $q_{f}=$ $0.73 \mathrm{~L} / \mathrm{min}$ (again, as occurs in Moog type 30 series 35 double nozzle-flapper servovalves [2,32]). Using a discharge pressure $p_{T}=1 \mathrm{bar}$ and a pump efficiency $\eta_{p}=0.7$, the avoided power consumption is $P_{a} \approx 0.07 \mathrm{~kW}$ in the first case $\left(p_{p}=70\right.$ bar and $\left.q_{f}=0.43 \mathrm{~L} / \mathrm{min}\right)$, and $P_{a} \approx 0.36 \mathrm{~kW}$ in the second case $\left(p_{p}=210\right.$ bar and $\left.q_{f}=0.73 \mathrm{~L} / \mathrm{min}\right)$. Considering that, in many applications, there are several valves working together and they can be in the rest position most of the time [33], one could deduce that the energy consumption avoided with the proposed solution can be remarkable in industrial and aeronautical applications.
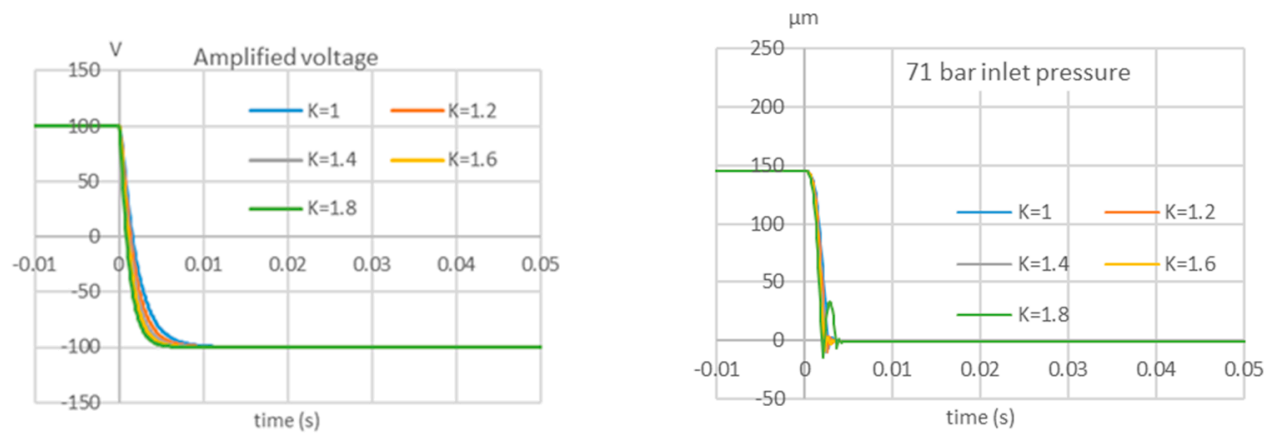

(a)
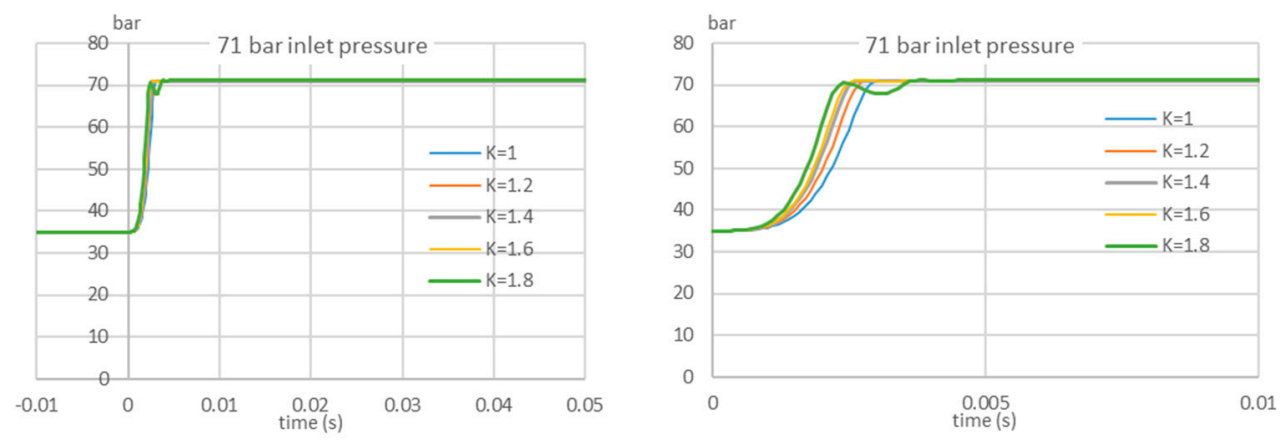

(b)

Figure 16. Amplified voltage and ring bender displacement (a) and pressure at point 7 with enlargement (b), simulated for an amplified voltage from $+100 \mathrm{~V}$ to $-100 \mathrm{~V}$ and for different values of the natural frequency of the amplifier: $\omega_{n}=\mathrm{k} \omega_{n, o}$ with $K=1,1.2,1.4,1.6,1.8$ (supply pressure $=71$ bar, $D=0.6 D_{0}$ and $\left.L=0.6 L_{0}, m=0.6 m_{0}\right)$.

\section{Conclusions}

This paper provides a novel architecture for the pilot stage of two-stage servovalves based on the use of piezo-electric actuators. In the proposed solution, the pilot stage is composed of two small (normally closed) 2/2 piezo-valves actuated by ring benders, which are compact elements providing good displacement and actuation forces. This novel configuration has the potential to overcome two main problems occurring in servovalves, namely, the complexity and the high quiescent flow (internal leakage) of the pilot stage. To assess the validity of the proposed solution, an experimental prototype of the $2 / 2$ piezo-valve was constructed and experimentally tested in a hydraulic test rig. The test rig reproduces the entire pilot stage for one side of the proposed valve architecture, being composed of the supply line, fixed restriction, piezo-valve and chamber between the fixed restriction, the spool end and the piezo-valve. In this way, the performance of the proposed architecture can be determined by measuring the time intervals taken to open and close the valve as well as to change the pilot pressure (namely, pressure at point 7 of the test rig). 
The step tests performed on the test rig show that the piezo-valve has a high potential in terms of response speed, since the time required for the displacement and for the pressure to change from $10 \%$ to $90 \%$ of their final values is less than $5 \mathrm{~ms}$. Repeated opening and closing procedures of the piezo-valve also show that the pilot pressure is maintained constant and equal to the supply pressure over time when the valve is closed, thus, proving that the quiescent flow is negligible compared to commercial units. The experimental data have also been used to validate a numerical model developed employing Simscape Fluids. This model has been used to show that, by acting on some crucial parameters, such as the volume of oil in the system, the mass of the moving parts and the natural frequency of the amplifier, the performance of the piezo-valve can be further improved.

Finally, a calculation procedure has been used to estimate that the power loss avoided thanks to the considerable reduction of the quiescent flow when the main valve is at rest can be as high as $0.36 \mathrm{~kW}$.

Author Contributions: All the authors contributed in formulating the problem, designing the research proposal, as well as writing, reviewing and editing the manuscript. All authors have read and agreed to the published version of the manuscript.

Funding: This research has been supported by the European Commission under the Marie Curie Intra-European fellowship Programme. EC Grant Agreement n. 701336, H2020 MSCA Individual Fellowship: Development of a novel servovalve concept for aircraft (DNSVCFA). Start date: 01/09/2017, End date: 19/10/2019, Location of the project: University of Bath.

Conflicts of Interest: The authors declare no conflict of interest.

\section{Nomenclature}

\begin{tabular}{|c|c|}
\hline$A_{r}$ & Restriction area $\left[\mathrm{mm}^{2}\right]$ \\
\hline C & Capacitance $[\mathrm{nF}]$ \\
\hline$C_{D}$ & Discharge coefficient \\
\hline$C_{r b}$ & Damping coefficient of the moving parts [Ns/m] \\
\hline$C_{\text {stop }}$ & Damping coefficient hard stop [Ns/m] \\
\hline D & Diameter of the hydraulic chamber [mm] \\
\hline$D_{0}$ & Diameter of the hydraulic chamber of the prototype [mm] \\
\hline$d$ & Diameter of the piezo valve orifice $[\mathrm{mm}]$ \\
\hline$E$ & Bulk modulus $\left[\mathrm{N} / \mathrm{m}^{2}\right]$ \\
\hline$E_{0}$ & Pure liquid bulk modulus $\left[\mathrm{N} / \mathrm{m}^{2}\right]$ \\
\hline$F_{\text {flow }}$ & Flow force $[\mathrm{N}]$ \\
\hline$F_{r b}$ & Actuation force of the ring bender $[\mathrm{N}]$ \\
\hline$I_{\max }$ & Maximum current $[\mathrm{A}]$ \\
\hline K & Proportional factor \\
\hline$K_{a}$ & Gain of the amplifier \\
\hline$K_{d, v}$ & Ring bender conversion factor [N/V] \\
\hline$K_{r b}$ & Spring stiffness of the ring bender $[\mathrm{N} / \mathrm{m}]$ \\
\hline$K_{\text {stop }}$ & Stiffness of the hard stop $[\mathrm{N} / \mathrm{m}]$ \\
\hline$L$ & Length of the hydraulic chamber [mm] \\
\hline$L_{0}$ & Length of the hydraulic chamber of the prototype [mm] \\
\hline$m$ & Mass of the moving parts $[\mathrm{kg}]$ \\
\hline$m_{0}$ & Mass of the moving parts of the prototype $[\mathrm{kg}]$ \\
\hline$n$ & Hysteresis non-linear term [V] \\
\hline$p$ & Absolute pressure $\left[\mathrm{N} / \mathrm{m}^{2}\right]$ \\
\hline$p_{0}$ & Atmospheric pressure $\left[\mathrm{N} / \mathrm{m}^{2}\right]$ \\
\hline$q$ & Volumetric flow rate $\left[\mathrm{m}^{3} / \mathrm{s}\right]$ \\
\hline$V_{a m p}$ & Voltage from the amplifier [V] \\
\hline$V_{c}$ & Control voltage $[\mathrm{V}]$ \\
\hline$x$ & Ring bender displacement [mm] \\
\hline$x_{\max }$ & Maximum displacement of the ring bender [mm] \\
\hline
\end{tabular}




$\begin{array}{ll}x_{\min } & \text { Minimum displacement of the ring bender [mm] } \\ x_{0} & \text { Pre-compression [mm] } \\ \alpha & \text { Parameter for the hysteresis formula } \\ \beta & \text { Parameter for the hysteresis formula } \\ \gamma & \text { Ratio of the specific heats } \\ \delta & \text { Parameter for the hysteresis formula } \\ \varepsilon & \text { Relative gas content at atmospheric pressure } \\ \xi & \text { Damping factor of the amplifier } \\ \rho_{0} & \text { Fluid density at atmospheric conditions }\left[\mathrm{kg} / \mathrm{m}^{3}\right] \\ \omega_{n} & \text { Natural frequency of the amplifier }[\mathrm{rad} / \mathrm{s}] \\ \omega_{n, 0} & \text { Natural frequency of the experimental amplifier }[\mathrm{rad} / \mathrm{s}]\end{array}$

\section{References}

1. Plummer, A.R. Electrohydraulic servovalves-Past, present, and future. In Proceedings of the 10th International Fluid Power Conference, IFK2016, Dresden, Germany, 8 March 2016; pp. 405-424.

2. Tamburrano, P.; Plummer, A.R.; Distaso, E.; Amirante, R. A review of electro-hydraulic servovalve research and development. Int. J. Fluid Power 2019, 20, 53-98. [CrossRef]

3. Chattopadhyay, H.; Kundu, A.; Saha, B.K.; Gangopadhyay, T. Analysis of flow structure inside a spool type pressure regulating valve. Energy Convers Manag. 2012, 53, 196-204. [CrossRef]

4. Saha, B.K.; Chattopadhyay, H.; Mandal, P.B.; Gangopadhyay, T. Dynamic simulation of a pressure regulating and shut-off valve. Comput Fluids 2014, 101, 233-240. [CrossRef]

5. Simic, M.; Herakovic, N. Reduction of the flow forces in a small hydraulic seat valve as alternative approach to improve the valve characteristics. Energy Convers Manag. 2015, 89, 708-718. [CrossRef]

6. Herakovic, N.; Duhovnik, J.; Simic, M. CFD simulation of flow force reduction in hydraulic valves. Teh. Vjesn. Tech. Gaz. 2015, 22, 555-564. [CrossRef]

7. Tamburrano, P.; Plummer, A.R.; Distaso, E.; Amirante, R. A review of direct drive proportional electrohydraulic spool valves: Industrial state-of-the-art and research advancements. J. Dyn. Syst. Meas. Control 2019, 141, 020801. [CrossRef]

8. Amirante, R.; Distaso, E.; Tamburrano, P. Sliding spool design for reducing the actuation forces in direct operated proportional directional valves: Experimental validation. Energy Convers. Manag. 2016, 119, 399-410. [CrossRef]

9. Amirante, R.; Distaso, E.; Tamburrano, P. Experimental and numerical analysis of cavitation in hydraulic proportional directional valves. Energy Convers. Manag. 2014, 87, 208-219. [CrossRef]

10. Amirante, R.; Catalano, L.A.; Poloni, C.; Tamburrano, P. Fluid-dynamic design optimization of hydraulic proportional directional valves. Eng. Optim. 2014, 46, 1295-1314. [CrossRef]

11. Bang, Y.B.; Joo, C.S.; Lee, K.I.; Hur, J.W.; Lim, W.K. Development of a two-stage high speed electrohydraulic servovalve systems using stacktype piezoelectric elements. In Proceedings of the IEEE/ASME international conference on advanced intelligent mechatronics (AIM 2003), Kobe, Japan, 20-24 July 2003; Volume 1, pp. 131-136. [CrossRef]

12. Branson, D.T.; Wang, F.C.; Johnston, D.N.; Tilley, D.G.; Bowen, C.R.; Keogh, P.S. Piezoelectrically actuated hydraulic valve design for high bandwidth and flow performance. Proc. Inst. Mech. Eng. Part I J. Syst. Control Eng. 2011, 225, 345-359. [CrossRef]

13. Reichert, M. High response hydraulic servovalve with piezo-actuators in the pilot stage. Olhydraulik Pneum. 2006, 12, 1-17.

14. Lindler, J.E.; Anderson, E.H. Piezoelectric direct drive servovalve. In Proceedings of the SPIE's 9th Annual International Symposium on Smart Structures and Materials, San Diego, CA, USA, 17-21 March 2002. [CrossRef]

15. Jeon, J.; Han, C.; Han, Y.M.; Choi, S.B. A new type of a direct-drive valve system driven by a piezostack actuator and sliding spool. Smart Mater. Struct. 2014, 23, 075002. [CrossRef]

16. Karunanidhi, S.; Singaperumal, M. Mathematical modelling and experimental characterization of a high dynamic servo valve integrated with piezoelectric actuator. Proc. Inst. Mech. Eng. Part I J. Syst. Control Eng. 2010, 224, 419-435. [CrossRef] 
17. Milecki, A. Modelling and investigation of electrohydraulic servovalve with piezo element. Proc. Inst. Mech. Technol. 2006, 26, 181-188.

18. Lihui, Z.; Shiju, E.; Xilin, Z.; Chunfu, G. Development of hydroelectric servovalve based on piezoelectric elements. In Proceedings of the 2010 International Conference on Mechanic Automation and Control Engineering MACE2010, Wuhan, China, 26-28 June 2010; pp. 3330-3333.

19. Guang-Ming, C.; Peng, L.I.; Zhi-Gang, Y.; Shi-ju, E.; Jian-fang, L.I. Double-nozzle piezoelectric servovalve. Guangxue Jingmi Gongcheng/Opt. Precis. Eng. 2005, 13, 276-282.

20. Bertin, M.J.F.; Plummer, A.R.; Bowen, C.R.; Johnston, D.N. An Investigation of Piezoelectric Ring Benders and Their Potential for Actuating Servo Valves. In Proceedings of the ASME/BATH 2014 Symposium on Fluid Power and Motion Control. ASME/BATH 2014 Symposium on Fluid Power and Motion Control, Bath, UK, 10-12 September 2014; V001T01A034. ASME: New York, NY, USA. [CrossRef]

21. Tamburrano, P.; Amirante, R.; Distaso, E.; Plummer, A.R. Full simulation of a piezoelectric double nozzle flapper pilot valve coupled with a main stage spool valve. Energy Procedia 2018, 148, 487-494. [CrossRef]

22. Grunwald, A.; Olabi, A.G. Design of a magnetostrictive (MS) actuator. Sens. Actuators A Phys. 2008, 144, 161-175. [CrossRef]

23. Zhu, Y.; Li, Y. Development of a deflector-jet electrohydraulic servovalve using a giant magnetostrictive material. Smart Mater. Struct. 2014, 23. [CrossRef]

24. Zhu, Y.; Yang, X.; Wang, X. Development of a four nozzle flapper servovalve driven by a giant magnetostrictive actuator. Proc. Inst. Mech. Eng. Part I J. Syst. Control Eng. 2015, 229, 293-307. [CrossRef]

25. Karunanidhi, S.; Singaperumal, M. Design, analysis and simulation of magnetostrictive actuator and its application to high dynamic servo valve. Sens. Actuators A Phys. 2010, 157, 185-197. [CrossRef]

26. Yang, Z.; He, Z.; Li, D.; Xue, G.; Cui, X. Hydraulic amplifier design and its application to direct drive valve based on magnetostrictive actuator. Sens. Actuators A Phys. 2014, 216, 52-63. [CrossRef]

27. Persson, L.J.; Plummer, A.R.; Bowen, C.R.; Brooks, I. Design and Modelling of a Novel Servovalve Actuated by a Piezoelectric Ring Bender. In Proceedings of the ASME/BATH 2015 Symposium on Fluid Power and Motion Control, ASME/BATH 2015 Symposium on Fluid Power and Motion Control, Chicago, IL, USA, 12-14 October 2015; V001T01A043. ASME: New York, NY, USA. [CrossRef]

28. Tamburrano, P.; Amirante, R.; Distaso, E.; Plummer, A.R. A Novel Piezoelectric Double-Flapper Servovalve Pilot Stage: Operating Principle and Performance Prediction. In Proceedings of the Bath/ASME Symposium on Fluid Power and Motion Control FPMC 2018, Bath, UK, 12-14 September 2018; University of Bath: Bath, UK, 2018.

29. Noliac. Available online: http://www.noliac.com/products/actuators/platestacks/ (accessed on 1 September 2017).

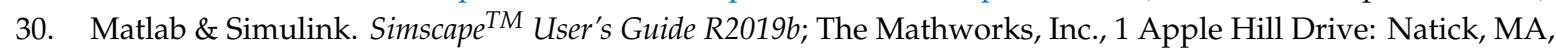
USA, 2019.

31. Merritt, H. Hydraulic Control System; John Wiley and Sons: New York, NY, USA; London, UK; Sydney, Australia, 1967.

32. Moog. Available online: http://www.moog.com/products/servovalves-servo-proportional-valves.html (accessed on 1 September 2017).

33. Bhatti, J.; Plummer, A.R. Hydraulic running robots: The prospects for fluid power in agile locomotion. In Proceedings of the 12th Scandinavian Conference on Fluid Power (SICFP'11), Tampere, Finland, 18-20 May 2011.

(C) 2020 by the authors. Licensee MDPI, Basel, Switzerland. This article is an open access article distributed under the terms and conditions of the Creative Commons Attribution (CC BY) license (http://creativecommons.org/licenses/by/4.0/). 